\title{
Early-Holocene simulations using different forcings and resolutions in AWI-ESM
}

\author{
Xiaoxu Shi, (D) Gerrit Lohmann, Dmitry Sidorenko and Hu Yang
}

\begin{abstract}
The earliest part of the Holocene, from II.5k to $7 \mathrm{k}(\mathrm{k}=1000$ years before present), is a critical transition period between the relatively cold last deglaciation and the warm middle Holocene. It is marked by more pronounced seasonality and reduced greenhouse gases (GHGs) than the present state, as well as by the presence of the Laurentide Ice Sheet (LIS) and glacial meltwater perturbation. This paper performs experiments under pre-industrial and different early-Holocene regimes with AWI-ESM (Alfred Wegener Institute-Earth System Model), a state-of-the-art climate model with unstructured mesh and varying resolutions, to examine the sensitivity of the simulated Atlantic meridional overturning circulation (AMOC) to early-Holocene insolation, GHGs, topography (including properties of the ice sheet), and glacial meltwater perturbation. In the experiments with early-Holocene Earth orbital parameters and GHGs applied, the AWI-ESM simulation shows a JJA (June-July-August) warming and DJF (December-January-February) cooling over the mid and high latitudes compared with pre-industrial conditions, with amplification over the continents. The presence of the LIS leads to an additional regional cooling over the North America. We also simulate the meltwater event around 8.2k. Big discrepancies are found in the oceanic responses to different locations and magnitudes of freshwater discharge. Our experiments, which compare the effects of freshwater release evenly across the Labrador Sea to a more precise injection along the western boundary of the North Atlantic (the coastal region of LIS), show significant differences in the ocean circulation response, as the former produces a major decline of the AMOC and the latter yields no obvious effect on the strength of the thermohaline circulation. Furthermore, proglacial drainage of Lakes Agassiz and Ojibway leads to a fast spin-down of the AMOC, followed, however, by a gradual recovery. Most hosing experiments lead to a warming over the Nordic Sea and Barents Sea of varying magnitudes, because of an enhanced inflow from lower latitudes and a northward displacement of the North Atlantic deep convection. These processes exist in both of our high- and low-resolution experiments, but with some local discrepancies such as (I) the hosing-induced subpolar warming is much less pronounced in the high-resolution simulations; (2) LIS coastal melting in the high-resolution model leads to a slight decrease in the AMOC; and (3) the convection formation site in the low- and high-resolution experiments differs, in the former mainly over northeastern North Atlantic Ocean, but in the latter over a very shallow subpolar region along the northern edge of the North Atlantic Ocean. In conclusion, we find that our simulations capture spatially heterogeneous responses of the early-Holocene climate.
\end{abstract}

\section{Keywords}

early-Holocene, freshwater perturbation, ice sheet

Received 30 October 20I5; revised manuscript accepted 17 January 2020

\section{Introduction}

The early Holocene (from $11.5 \mathrm{k}$ to $7 \mathrm{k}$ ) in our present interglacial period is marked by pronounced seasonality and by the presence of the Laurentide Ice Sheet (LIS). Even though recent data syntheses have improved our understanding of reconstructed data for paleoperiods (Bigelow et al., 2003; Mügler et al., 2010), discrepancies between various records still make it difficult to obtain a comprehensive look at early-Holocene climate change (Bradley, 1990; Larocque and Bigler, 2004; Liu et al., 2014; Rao et al., 2019). Numerical climate model simulations can be used to improve our understanding of the mechanism behind the earlyHolocene climatic changes and to provide a coherent and physically consistent overview of the climate on all timescales.

One of the main applications of climate models has been to explore the climatic effects of the Earth's changed orbital parameters. Applying early-Holocene precession and obliquity of the Earth, Kutzbach (1981) found an intensified continental-scale monsoon circulation. Using an atmospheric model coupled to a mixedlayer ocean, Mitchell et al. (1988) found Northern Hemisphere warming throughout the year. Kutzbach and Gallimore (1988) performed a similar simulation indicating that the continents were warmer in summer and that northern summer monsoons were more intense in the early Holocene than at present. Simulations with climate models have shown that the wetter conditions in the Sahel and Sahara regions were probably caused by changes in Earth's orbital parameters that increased the amplitude of the seasonal solar radiation cycle in the Northern Hemisphere (Kutzbach et al., 1996). In a transient simulation of the Holocene climate with ECBilt orbital forcing, Weber (2001) observed that summer warming over land induces a stronger monsoon circulation in the subtropics and an associated adjustment in precipitation patterns. An Earth system model of intermediate complexity, MoBidiC, has been used to simulate the transient variations in continental temperature, sea surface temperature (SST), thermohaline circulation, and sea-ice cover

Alfred Wegener Institute, Helmholtz Center for Polar and Marine Research, Bremerhaven, Germany

\section{Corresponding author:}

Gerrit Lohmann, Alfred Wegener Institute, Helmholtz Center for Polar and Marine Research, Bussestr. 24, 27570 Bremerhaven, Germany. Email: Gerrit.Lohmann@awi.de 
over the last 9000 years (Crucifix et al., 2002). Synthetic records of glacier length have been generated for the Holocene epoch using a process-based glacier model coupled to the intermediate-complexity climate model ECBilt, forced by changes in insolation due to variations in the Earth's orbital parameters (Weber et al., 2004; Weber and Oerlemans, 2003). It has been suggested that increased ablation due to enhanced early-Holocene boreal-summer insolation was the predominant cause of the retreat of the LIS (Carlson et al., 2008).

The greenhouse gases (GHGs) are another important factor for the climate. Records of past GHGs have been established in numerous studies (Argus et al., 2014; Köhler et al., 2017; Raynaud et al., 2000). Atmospheric $\mathrm{CO}_{2}$ content rised by 20-30 ppm from the early Holocene to the present. According to the formula for calculating radiative forcing based on changed atmospheric $\mathrm{CO}_{2}$ levels (Myhre et al., 1998), such an anomaly can create a radiation change of about $0.5 \mathrm{~W} / \mathrm{m}^{2}$. The $\mathrm{CH}_{4}$ content decreased by about $70 \mathrm{ppb}$ until $5 \mathrm{k}$ and then increased again by $130 \mathrm{ppb}$ from $5 \mathrm{k}$ to $0 \mathrm{k}$. Atmospheric $\mathrm{N}_{2} \mathrm{O}$ also shows a general increase from 260 to $270 \mathrm{ppb}$. Performing transient simulations with separate forcings, Renssen et al. (2009) found that the effect of GHGs alone is of minor importance as compared with orbital forcing. For example, summer temperatures north of $60^{\circ} \mathrm{N}$ are $2 \mathrm{~K}$ warmer at $9 \mathrm{k}$ than at present with orbital forcing, but the effect of greenhouse forcing alone was a slight warming of only $0.3 \mathrm{~K}$ over the past 9000 years. Over a longer time period, however (such as from $22 \mathrm{k}$ to $0 \mathrm{k}$ ), the modeling experiment by CCSM3 indicated that $\mathrm{CO}_{2}$ was the major driver of temperature variance, explaining $70 \%$ of the high northern latitude warming (Liu et al., 2009). $\mathrm{CO}_{2}$ variance is also found to have played a role in East Asian monsoon precipitation over the last $21 \mathrm{k}$ (Lu et al., 2013).

Positioned at mid-latitudes of the Northern Hemisphere, the continental ice sheets have been of crucial importance for the climate conditions of both glacial and interglacial periods alike. They influences the climate in three main ways: increased elevation, enhanced surface albedo, and meltwater drainage. Wei and Lohmann (2012) conducted two early-Holocene experiments using a coarse-resolution model COSMOS, one with $9 \mathrm{k}$ and the other with $0 \mathrm{k}$ topography (referred to as $\mathrm{H} 9 \mathrm{KT}$ and $\mathrm{H} 9 \mathrm{KO}$ ), and they found a strong cooling (more than $-10 \mathrm{~K}$ ) directly over the LIS due to the combined effect of higher surface elevation and surface albedo in H9KT compared with $\mathrm{H} 9 \mathrm{KO}$, as well as an increase in the Atlantic meridional overturning circulation (AMOC; more than $6 \mathrm{~Sv}$ ). This was explained by the cooling effect of the ice sheet which increased the surface water density and thus enhanced deep-water formation. In terms of glacial and interglacial cycles, the abrupt climate shifts embodied in the Dansgaard-Oeschger (DO) events have been found to be controlled by changes in ice-sheet elevation (Zhang et al., 2014). Moreover, major changes in the climate of North America have been attributed to the orographic effect of the LIS during Last Glacial Maximum (LGM; Broccoli and Manabe, 1987). To our knowledge, these previous studies have been focused either on the combined effect of surface elevation and albedo over the LIS, or solely on elevation. Thus, the albedo effect has so far not been solely examined, although there have been efforts to understand Greenland ice-sheet albedo feedback in the modern climate (Box et al., 2012).

Ice core records from Greenland offerred convincing evidence for an abrupt cold event around 8.2k (Alley et al., 1997). Its proposed cause was a meltwater pulse and associated perturbation of the North Atlantic thermohaline circulation (Barber et al., 1999; Von Grafenstein et al., 1998). Previous studies have suggested that the meltwater pulse consisted of two different types: one, the outburst of Lakes Agassiz and Ojibway (Barber et al., 1999); the other, additional background freshwater fluxes that went on for several centuries (Carlson et al., 2009). The combined effect of these two types of LIS meltwater forcing on the early-Holocene climate has been investigated with a variety of coupled models. Simulating solely the lake discharge in climate models by prescribing a meltwater input of $2.5 \mathrm{~Sv}$ in a single year resulted in a climate perturbation that recovers over several decades (Morrill et al., 2013b; Wagner et al., 2013). As for the background freshwater fluxes, they have been the subject of a greater number of studies assuming various hosing rates. For example, a fixed amount of freshwater discharged into the Labrador Sea at three different rates has been applied in a global coupled atmospheresea ice-ocean model, ECBilt-CLIO-VECODE, by Renssen et al. (2002). The results demonstrated that several types of recovery might have existed given the same kind of meltwater perturbation. One of their simulations, in a scenario with a 20 -year pulse, produced a model response in agreement with proxy records (Renssen et al., 2001, 2009); a more gradual release of $0.03 \mathrm{~Sv}$ as Klitgaard-Kristensen et al. (1998) proposed resulted in no significant thermohaline circulation change (Renssen et al., 2001). Wei and Lohmann (2012) prescribed a freshwater forcing of $0.09 \mathrm{~Sv}$ into the North Atlantic Ocean between $40^{\circ} \mathrm{N}$ and $60^{\circ} \mathrm{N}$, which led to significant surface cooling and a decline in the AMOC. To combine the effect of both lake release and background freshwater input, Matero et al. (2017) applied a 2-year freshwater pulse of $1.25 \mathrm{~Sv}$ in an early-Holocene simulation with an already-given long-term background flux of $0.05 \mathrm{~Sv}$; however, this scenario produced no distinct temperature anomaly over Greenland. But similar experiments performed by Wagner et al. (2013) - only with larger background freshwater flux - showed a continuous decline in the AMOC as well as cooling of Greenland.

Most of the above studies focus on the effects of ice-sheet and glacial meltwater flux on the simulated climate; but they have applied a relatively coarse resolution. This paper applies a finiteelement climate model, AWI-ESM (Alfred Wegener InstituteEarth System Model), with unstructured mesh and various resolutions, to simulate the early-Holocene climate. Our experiments are forced by early-Holocene regimes involving the solar insolation and the GHGs content, and their combination with the presence of the LIS including its elevation and albedo. Furthermore, we perform two different types of hosing experiments by adding freshwater flux into either the western boundary of the North Atlantic (the coastal region of LIS) or into the Labrador Sea. These experiments are performed at two different resolutions. We also conduct another hosing simulation reflecting the proglacial lake release. To our knowledge, it is the first earlyHolocene simulation using a triangle-mesh high-resolution climate model. We would like to explore how the early-Holocene climate can be seen to differ when simulated at low and high resolutions, and the extent to which it is affected by the locations and variabilities of freshwater input.

The remainder of this paper is structured as follows. Section 'Methodology' describes the model we use and the experimental design. Section 'Results' presents the results with respect to anomalous surface and oceanic properties in the early Holocene as compared with the pre-industrial period. Sections 'Discussion' and 'Conclusion', respectively, discuss the results and our conclusions.

\section{Methodology}

\section{Model description}

The AWI-ESM is a newly developed global coupled climate model which has been established at the AWI. The ocean and seaice component is the Finite-Element Sea Ice-Ocean Model (FESOM; Danabasoglu et al., 2016; Danilov et al., 2004; Rackow et al., 2018; Sidorenko et al., 2011, 2015; Timmermann et al., 2009; Wang et al., 2014), which is discretized on a triangular grid with a continuous conforming representation of model variables, 
Table I. List of experiments and boundary conditions.

\begin{tabular}{|c|c|c|c|c|c|c|}
\hline Experiment & Insolation & $\begin{array}{l}\text { Greenhouse } \\
\text { gases }\end{array}$ & $\begin{array}{l}\text { Topography } \\
\text { and ice sheet }\end{array}$ & Freshwater flux & $\begin{array}{l}\text { Freshwater } \\
\text { region }\end{array}$ & $\begin{array}{l}\text { Integration } \\
\text { time }\end{array}$ \\
\hline CTR & Present & Present & Present & 0 & 0 & 1000 \\
\hline $\mathrm{EHOK}$ & 9 ka & 9 ka & Present & 0 & 0 & 800 \\
\hline EH9 K & $9 \mathrm{ka}$ & $9 \mathrm{ka}$ & $9 \mathrm{ka}$ & 0 & 0 & 800 \\
\hline FWFC & $9 \mathrm{ka}$ & $9 \mathrm{ka}$ & $9 \mathrm{ka}$ & $0.15 \mathrm{~Sv}$ & LIS coast & 100 \\
\hline FWFL & $9 \mathrm{ka}$ & $9 \mathrm{ka}$ & $9 \mathrm{ka}$ & $0.15 \mathrm{~Sv}$ & Labrador Sea & 100 \\
\hline CTRh & Present & Present & Present & 0 & 0 & 1000 \\
\hline $\mathrm{EHOKh}$ & $9 \mathrm{ka}$ & $9 \mathrm{ka}$ & Present & 0 & 0 & 800 \\
\hline EH9Kh & $9 \mathrm{ka}$ & $9 \mathrm{ka}$ & $9 \mathrm{ka}$ & 0 & 0 & 2000 \\
\hline FWFCh & $9 \mathrm{ka}$ & $9 \mathrm{ka}$ & $9 \mathrm{ka}$ & $0.15 \mathrm{~Sv}$ & LIS coast & 100 \\
\hline FWFLh & $9 \mathrm{ka}$ & $9 \mathrm{ka}$ & $9 \mathrm{ka}$ & $0.15 \mathrm{~Sv}$ & Labrador Sea & 100 \\
\hline FWFLh_lake & $9 \mathrm{ka}$ & $9 \mathrm{ka}$ & $9 \mathrm{ka}$ & $2.5 \mathrm{~Sv}(1)+0.13 \mathrm{~Sv}(99)$ & Labrador Sea & 100 \\
\hline
\end{tabular}

whereas the atmospheric module is represented by the general circulation model ECHAM6 (Stevens et al., 2013), mainly developed by the Max Planck Institute for Meteorology (MPI-M).

ECHAM6 is the sixth generation of the atmospheric general circulation model ECHAM; it focuses on coupling between diabatic processes, which are often associated with small-scale fluid dynamics and large-scale circulations. The model stems from an earlier release of the European Centre (EC) for Medium-Range Weather Forecasts (ECMWF) model (Roeckner et al., 1989). Like most models, the dynamics of ECHAM6 is based on hydrostatic primitive equations (HPEs) with traditional approximation. A Gaussian grid is used in the model to calculate non-linear equation terms and some physical representations. The boundary layer and turbulence parameterization are based on the eddy-diffusivity and -viscosity approach. Momentum transport arising from boundary effects is parameterized using the subgrid orography scheme as described by Lott (1999). Subgrid-scale cloudiness is represented using the assumed humidity distribution function scheme developed by Sundqvist et al. (1989). Radiative transfer in ECHAM6 is represented using the rapid radiation transfer (Iacono et al., 2008). ECHAM6 also includes a land surface model (JSBACH) based on a tiling of the land surface and includes dynamic vegetation with 12 plant functional types and 2 types of bare surface (Loveland et al., 2000; Raddatz et al., 2007).

FESOM is a hydrostatic ocean circulation model based on the finite-element approach and designed to work on unstructured meshes; it is therefore different in many important respects from models formulated on regular meshes. For example, an advantage of FESOM is its multi-resolution capability, which allows for regional focus in an otherwise global setup (Sidorenko et al., 2011). The flexibility of the unstructured meshes allows us to avoid the effect of geographic coordinates, so the meshes can be designed according to the distances along the spherical surface (Wang et al., 2014). In traditional models, the important basin exchange through many key passages - such as the Bering Strait, the Strait of Gibraltar, the Indonesian Throughflow, or the Canadian Arctic Archipelago (CAA) - is very hard to resolve because they are too narrow. Unstructured meshes enable narrow straits to be represented as throughflows (Wekerle, 2013). The mesh nodes are vertically aligned to avoid difficulties in resolving the hydrostatic balance. The model uses variable resolution, which can be as fine as $20 \mathrm{~km}$ in the Arctic and along coastlines. A no-slip boundary condition along the coast is implemented in the model. Surface stress and buoyancy fluxes are derived from the iceocean coupling. The FESOM sea ice component is a dynamicthermodynamic sea ice model with the Parkinson and Washington (1979) thermodynamics. The model consists of subgrid-scale processes based on Redi (1982), a so-called zero-layer approach borrowed from Semtner (1976), and a submodel of ice dynamics according to an elastic-viscous-plastic rheology (Hunke and
Dukowicz, 1997). The model also includes a prognostic snow layer (Owens and Lemke, 1990). Snow-ice conversion is parameterized based on Leppäranta (1983). The FESOM model has been validated in Timmermann et al. (2009) and Scholz et al. (2013), as has been the coupled model, AWI-ESM, in more recent studies (Rackow et al., 2018; Sidorenko et al., 2015).

AWI-ESM employs the OASIS3-MCT coupler (Valcke et al., 2013) with an intermediate regular exchange grid. Mapping between the intermediate grid and the atmospheric/oceanic grid is handled with bilinear interpolation. The atmosphere component, ECHAM6, computes 12 air-sea fluxes based on four surface fields provided by the ocean module FESOM. Every $6 \mathrm{~h}$, the coupler maps the mean fields and accumulated fluxes between model components.

\section{Experimental design}

In the following, we describe the experimental setup of 11 simulations. A summary of the experiment characteristics is also provided in Table 1.

Using the circulation model AWI-ESM at a low oceanic resolution as described in Figure 1a, we perform several experiments: a pre-industrial control experiment (CTR), plus four different early-Holocene runs (EH0 K, EH9 K, FWFC, and FWFL), all by prescribing the appropriate boundary conditions (Table 1). Orbital parameters are calculated according to Berger (1978). In the CTR experiment, the GHGs are prescribed according to the Paleoclimate Modeling Intercomparison Project (PMIP; Crucifix et al., 2005). In the early-Holocene simulations, the GHGs are taken from ice-core records and from recent measurements of firn air and atmospheric samples (Argus et al., 2014; Köhler et al., 2017). In EH0 K, the topography and ice-sheet properties are kept the same as in the CTR experiment, whereas in the other early-Holocene experiments, we use a reconstruction from the ice-sheet model ICE5G (VM2; Peltier, 2004). The model uses adjusted icesheet properties; for instance, the surface albedo is set to 0.7 , and the amount of vegetation to zero.

Previous studies have identified two types of freshwater input: type 1, the long-term background melting of the ice sheets (Carlson et al., 2009), particularly the LIS; and type 2, the sudden release of Lakes Agassiz and Ojibway around 8.2k (Barber et al., 1999). We examine the effects of long-term background freshwater flux (type 1) in the group of simulations labeled FWFC and FWFL, in which we additionally prescribe a forcing of freshwater perturbation by adding $0.15 \mathrm{~Sv}\left(1 \mathrm{~Sv}=1 \times 10^{6} \mathrm{~m}^{3} / \mathrm{s}\right)$ freshwater pulse into the coastal region of LIS and the whole area of Labrador Sea, respectively (see Supplementary Figure S1, available online). The total amount of released freshwater is about $4.67 \times$ $10^{14} \mathrm{~m}^{3}$, a value at the higher end of estimates of reconstructed meltwater releases for the $8.2 \mathrm{k}$ event (Von Grafenstein et al., 
(a)

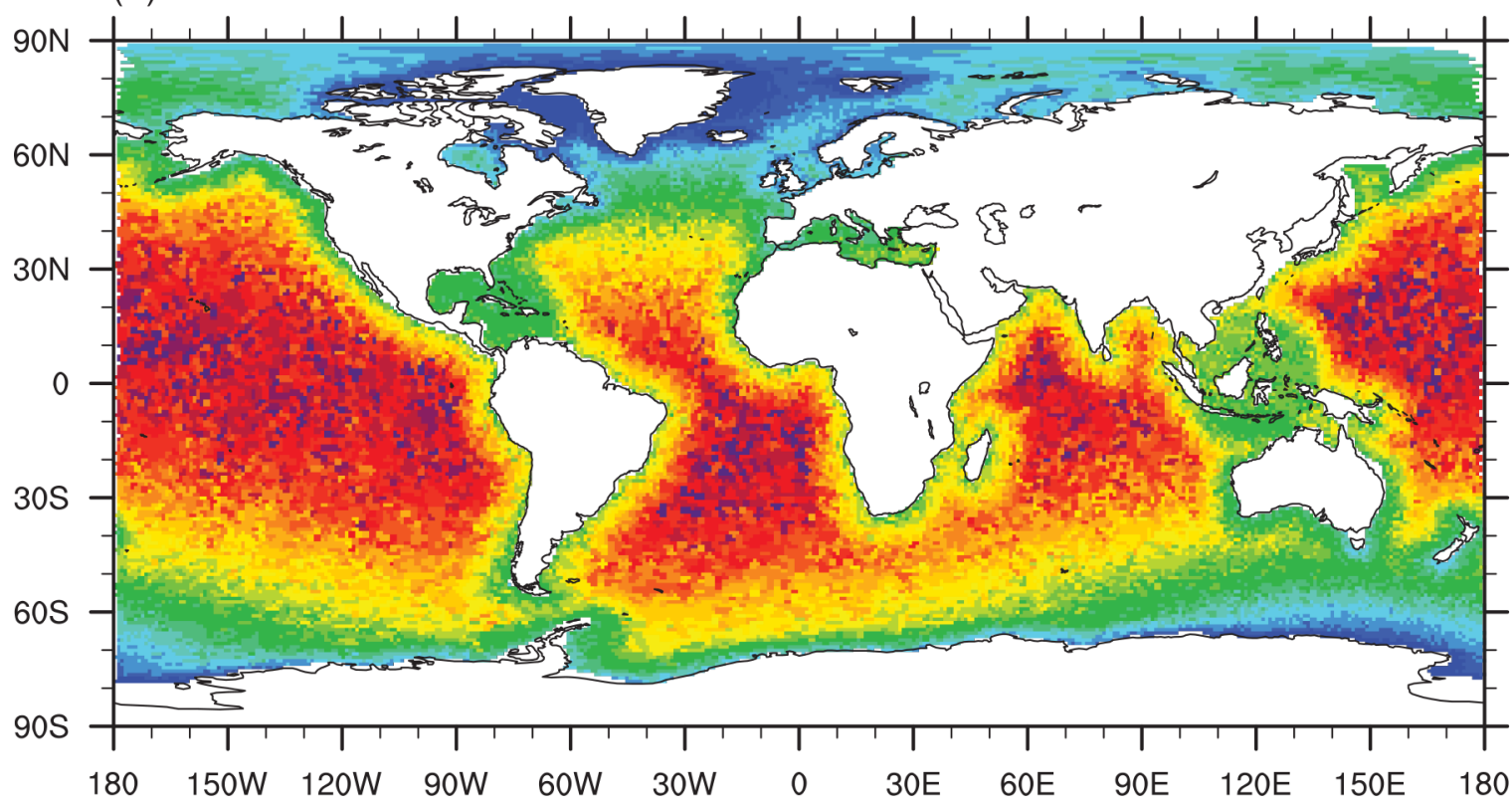

(b)
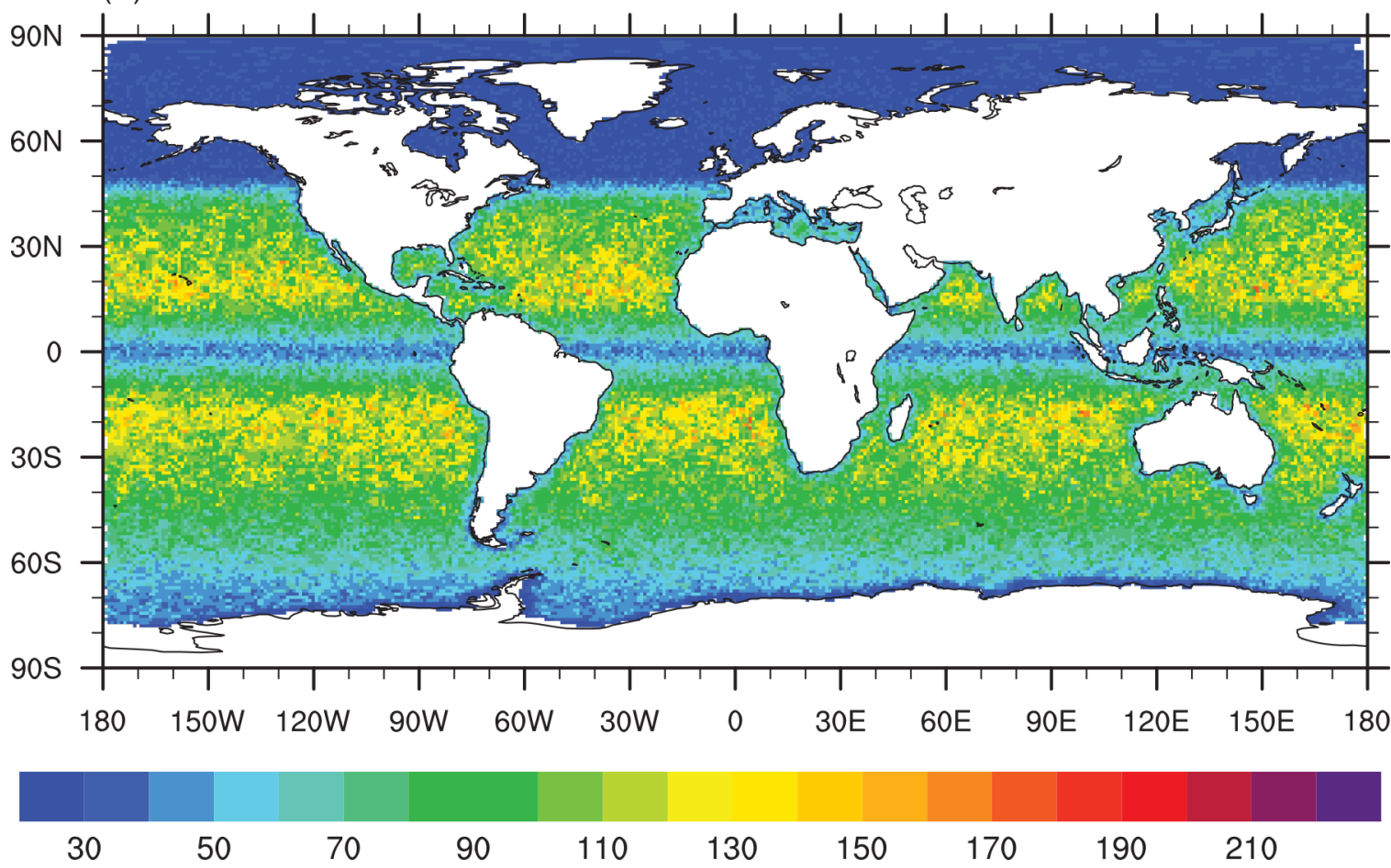

Figure I. FESOM mesh resolution applied in (a) CTR and (b) CTRh. Units are km.

1998). These two early-Holocene hosing experiments enable us to evaluate the sensitivity of the models to type 1 freshwater forcing. It should be noted that the FWFC and FWFL experiments do not take the sudden drainage of Lakes Agassiz and Ojibway into consideration.

The control experiment is initialized by the mean climatology from an Atmospheric Model Intercomparison Project (AMIP) and data from the World Ocean Atlas (WOA). It is integrated for 1000 years at T63L47 resolution (about $1.9^{\circ} \times 1.9^{\circ}, 47$ vertical levels) for the atmosphere component, and at varying resolutions as shown in Figure 1a with 46 vertical levels for the ice-ocean component. Both the EH0 K and EH9 K simulations start from a 460year middle-Holocene run and are integrated for an additional 800 years. The simulations are run long enough for the climate trends of the final 200 years to be small, which is then considered to represent the climatology of the respective simulation. The
FWFC and FWFL experiments start from the EH9 K experiment and integrate for 100 model-years with freshwater perturbation.

We also repeat the experiments introduced above (CTR, EH0 $\mathrm{K}$, EH9 K, FWFC, and FWFL) at high oceanic resolution as shown in Figure $1 \mathrm{~b}$; these we designate respectively as CTRh, EH0Kh, EH9Kh, and FWFLh. Then, initialized from the EH9Kh experiment, we perform three hosing experiments. And in addition to FWFCh and FWFLh - which apply a freshwater flux of $0.15 \mathrm{~Sv}$ into the LIS coastal and Labrador Sea regions, respectively, just as in the FWFC and FWFL experiments - we conduct a further hosing experiment which examines both the release of proglacial lakes Agassiz and Ojibway (type 2 freshwater input) and the type 1 background freshwater flux (FWFLh_lake). Following Otto-Bliesner et al. (2017), in the experiment FWFLh lake, we impose a single input of $2.5 \mathrm{~Sv}$ freshwater for 1 year followed by a background freshwater flux of $0.13 \mathrm{~Sv}$ for 99 years. 
This freshwater is added across the Labrador Sea, the same region as in FWFLh. The topography and ice sheet in this set of higher resolution experiments are based on more recent studies (Peltier et al., 2015).

\section{Results}

In terms of our statistical analysis for the timeslice experiments, we only take into account the integration periods after the spin-up - with trends in global SST not exceeding $0.05^{\circ} \mathrm{C}$ per century and a stable AMOC, according to Braconnot et al. (2007). Once runs were initiated for the timeslice experiments (i.e. CTR, CTRh, $\mathrm{EH} 0 \mathrm{~K}, \mathrm{EH} 0 \mathrm{Kh}, \mathrm{EH} 9 \mathrm{~K}$, and EH9Kh), no changes to the forcing were permitted. Consequently, all of the simulated climatic fluctuations are generated by internal climate variability in the coupled system. The seasonal and annual mean climatology is calculated by averaging the corresponding parameters over the entire valid integration periods. In the following, we explore the climate responses to different early-Holocene forcings.

\section{Impact of $9 \mathrm{k}$ insolation and GHGs}

The simulated surface temperature anomalies in $\mathrm{EH} 0 \mathrm{~K}$ compared with CTR are depicted in Figure 2a-c. A significant boreal-winter cooling of up to $-4 \mathrm{~K}$ compared with pre-industrial conditions, forced by the negative DJF (December-January-February) insolation anomalies, is found over the Northern Hemisphere in EH0 K (Figure 2a), especially over North America, Eurasia, and northern Africa. A local warming in the Nordic Sea is induced by a stronger southwest wind blowing across the relatively warmer surface of the North Atlantic Ocean. In boreal summer, the key feature of $\mathrm{EH} 0 \mathrm{~K}$ is a general warming of about $3 \mathrm{~K}$ that finds greater expression over the continents of the Northern Hemisphere (Figure $2 b$ ). The dominant cooling of annual mean temperature values results from the combined effect of the insolation changes and reduced GHGs (Figure 2c); the most pronounced cooling is found over the Sahel zone and is related both to reduced insolation in boreal winter as well as increased precipitation in boreal summer. The surface temperature anomalies in our high-resolution model (Figure $2 \mathrm{~g}-\mathrm{i})$ show similar patterns, though with more pronounced warming over the Bellingshausen Sea and the continents of the Northern Hemisphere in JJA (June-July-August).

The AMOC streamfunction - defined as the zonally integrated transport over the Atlantic basin - has respective averaged values of about 13.3 and $15.4 \mathrm{~Sv}\left(1 \mathrm{~Sv}=10^{6} \mathrm{~m}^{3} / \mathrm{s}\right)$ in the pre-industrial experiments CTR and CTRh (Figure $3 b$ and d). Compared with the corresponding pre-industrial state, the strength of the AMOC increases by 2.1 and $0.7 \mathrm{~Sv}$ in $\mathrm{EH} 0 \mathrm{~K}$ and $\mathrm{EH} 0 \mathrm{Kh}$, respectively (Figure $3 \mathrm{a}$ and $\mathrm{c}$ ). To examine the mechanisms behind AMOC anomalies, we next analyze the elements affecting deep-water formation in the North Atlantic Ocean, involving mixed-layer depth (MLD), sea water properties over the North Atlantic and atmospheric circulation.

The ocean mixed layer is the instantaneously mixed surface layer. Supplementary Figure S2 (available online) shows MLD in CTR and CTRh for boreal winter. Three main deep-water formation sites simulated by the high-resolution model are located in the Labrador Sea (deeper than $500 \mathrm{~m}$ ), in the ocean south of Iceland (up to $400 \mathrm{~m}$ ), and in the Norwegian coastal region (up to $300 \mathrm{~m}$ ). Lower resolution CTR depicts shallow MLD in the Labrador Sea because of an excessive simulated sea-ice cover extending into the northwestern North Atlantic Ocean. Surprisingly, the deep-water formation region in CTR centers in the northeastern North Atlantic Ocean (deeper than $500 \mathrm{~m}$ ).

The boreal-winter MLD anomaly pattern in EH0 K as compared with CTR, depicted in Figure 4a, is generally dominated by increased MLD over the Irminger and Nordic seas. At higher resolution, EH0Kh yields a generally deeper MLD in the Labrador and Irminger seas, but slightly shallower MLD in the Nordic Sea.

The response of SST to early-Holocene insolation and GHGs is depicted in Figure 5a and c. The model produces a general global cooling, especially across the tropical and subtropical regions, induced mostly by reduced insolation in boreal winter. Another important signal is an increase in Southern Ocean SST dominated by a positive insolation anomaly from September to November. The annual mean sea surface salinity (SSS) anomalies are shown in Figure 6. Compared with pre-industrial conditions, the most intriguing large-scale features in EH0 K (Figure 6a) include the following: (1) the salinification over the North Atlantic Ocean and the Nordic Sea; (2) the increase and decrease in SSS over the equatorial Pacific and Indian Ocean, respectively, likely led by the corresponding change in precipitation; and (3) general freshening over the central Arctic as a result of lower seaice production. At higher resolution, EHOKh produces a slightly freshened North Atlantic Ocean and Nordic Sea, as well as a local salinification over the Gulf Stream (Figure 6c).

Figures 7 and 8 represent the meridional profiles of zonal mean temperature and salinity along the Atlantic section. At low resolution, a general cooling is found in $\mathrm{EH} 0 \mathrm{~K}$ at depths of 0-1000 m. Moreover, salinification and freshening occurs over the upper ocean north and south of $30^{\circ} \mathrm{N}$, respectively, contributing to an increased meridional density gradient; and that results further in a strengthening of the thermohaline circulation. The high-resolution experiment $\mathrm{EH} 0 \mathrm{Kh}$ results in a generally cooler and fresher ocean but with a local warming in the tropical subsurface layer.

Figure 9 depicts the changes in sea-level pressure (SLP). Compared with pre-industrial conditions, both low- and highresolution runs (EH0 K and $\mathrm{EHOKh}$ ) illustrate a North Atlantic Oscillation (NAO)-like mode, with negative SLP anomalies over the Greenland and Nordic seas and positive anomalies over the North Atlantic Ocean (Figure 9a and c). Another intriguing feature is a more negative Southern Annular Mode (SAM) which is more pronounced in low-resolution experiment (EH0 K). In addition, the early-Holocene favors high SLP over the Okhotsk Sea, northern Africa, and southern Eurasia.

Given above, we can find that both EHO K and EHOKh reveal general deeper MLD over the main deep-water formation sites, which is associated with the strengthening of AMOC. However, the causes of the MLD anomalies are different: In EHO K, the salinification over the North Atlantic subpolar water plays a significant role in enhancing the deep convection. In EH0Kh, only a slight freshening (about $-0.2 \mathrm{psu}$ ) is obtained over the surface of North Atlantic Ocean. We propose that the MLD changes in EH0 $\mathrm{K}$ and $\mathrm{EHOKh}$ are also related to atmospheric circulation. As shown in Supplementary Figure S3 (available online), during $\mathrm{NAO}+$ years, the mixed layer over the main deep-water formation sites becomes deeper. The linkage between NAO and AMOC is through latent and sensible heat fluxes. Let us now consider the (latent + sensible) heat flux anomalies associated with the NAO. The shaded regions in Supplementary Figure S4 (available online) represent the dipole anomaly in ocean-atmosphere heat flux over the North Atlantic Ocean. During NAO+, the anomalous (latent + sensible) heat flux is upward to the north and downward to the south, which can strengthen the thermal gradients. Such dipole pattern centers in different regions in low- and high-resolution models. In CTR, it is located mainly over the northeastern North Atlantic and in CTRh, the Labrador Sea, where the deep convection mainly occurs (Supplementary Figure S2, available online). Therefore, we conclude that the NAO-related atmospheric circulation can attribute to $9 \mathrm{k}$ AMOC. It should also be noted that the AMOC change in EHOKh is only $0.7 \mathrm{~Sv}$ relative to CTRh, which is not significant compared with the variability of the AMOC (about $1 \mathrm{~Sv}$ ). 


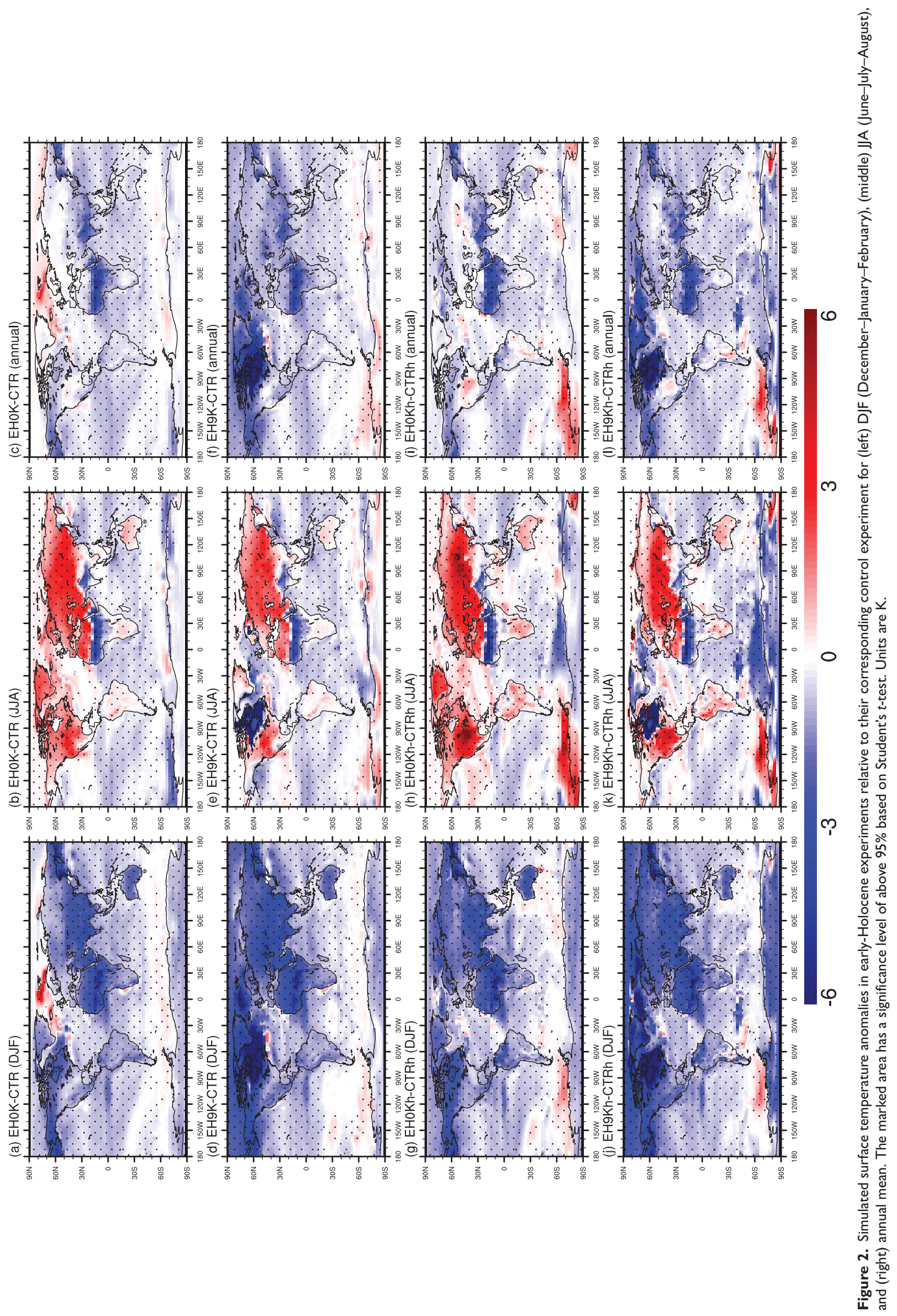


(a) Low resolution

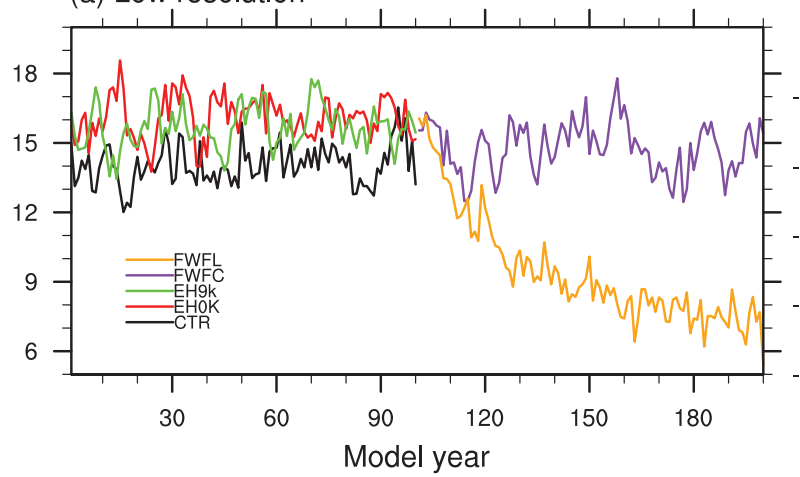

(c) High resolution

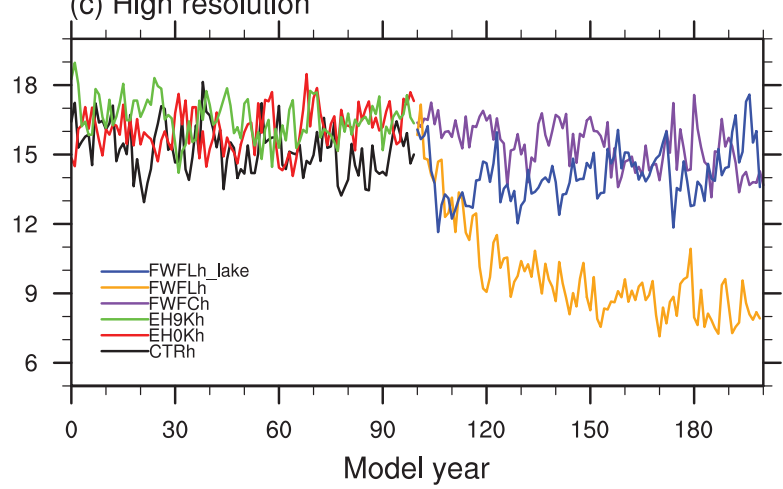

(b) Low resolution

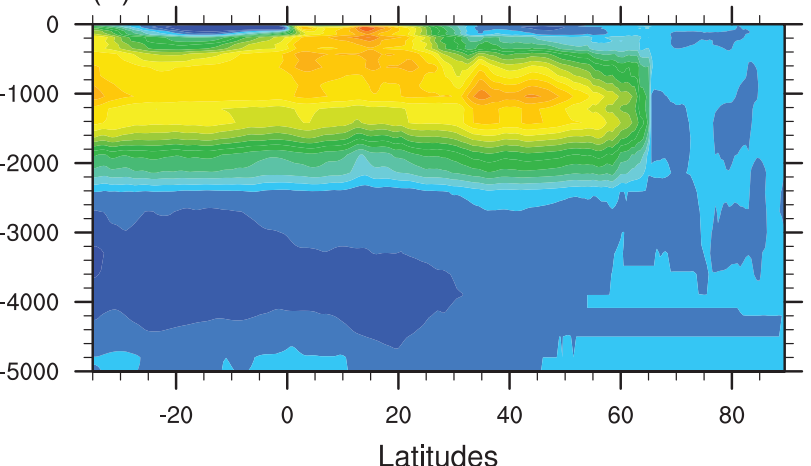

(d) High resolution

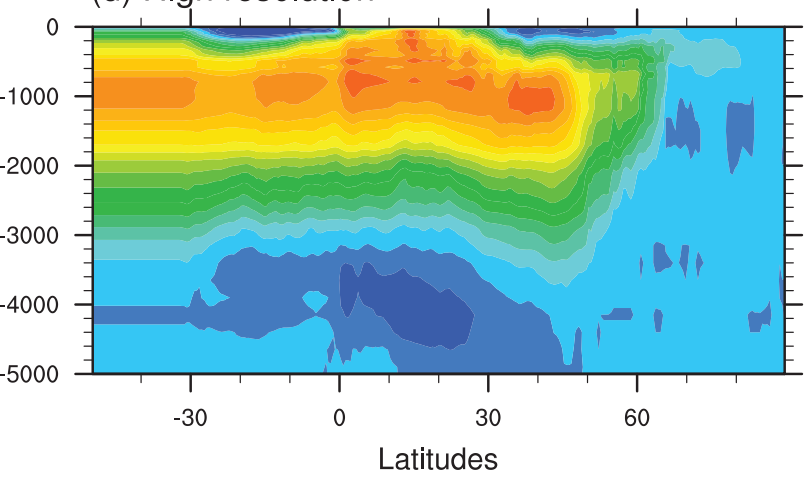

Figure 3. (a, c) Simulated annual mean AMOC strength in (a) low-resolution and (c) high-resolution experiments. (b, d) Simulated annual mean pre-industrial AMOC streamfunction in (b) low-resolution and (d) high-resolution experiments. Units are Sv.

\section{Impact of $9 k$ topography and ice sheet}

Changes in the topography and ice sheet have a considerable global influence. In the EH9 K experiment, a large cooling (more than -10 K) occurs over the prescribed continental ice sheet of North America throughout the year (Figure 2d-f) and is attributed to the higher elevation and high surface albedo of the LIS. In boreal summer, the strong LIS cooling overcompensates the positive insolation anomaly and spreads further to Baffin Bay and the North Atlantic Ocean (Figure 2e). As a result, annual mean values (Figure 2f) are cooler than they are in CTR and EH0 K. No significant change is found for the Antarctic continent and Southern Ocean in EH9 K, with the exception of a slight cooling in DJF indicating a minor effect of the increased Antarctic elevation. Similar patterns of the temperature anomalies are shown in high-resolution model (Figure $2 \mathrm{j}-1$ ).

The oceanic responses in $\mathrm{EH} 9 \mathrm{~K}$ and $\mathrm{EH} 9 \mathrm{Kh}$ just resemble that in $\mathrm{EH} 0 \mathrm{~K}$ and $\mathrm{EH} 0 \mathrm{Kh}$, respectively, even though with different magnitudes. One clear exception is a pronounced cooling up to $-2 \mathrm{~K}$ over the North Atlantic and the Nordic Sea (Figure $5 \mathrm{~b}$ and d), caused by the persisted LIS.

Compared with EH0 K and EH0Kh, the AMOC in EH9 K and $\mathrm{EH} 9 \mathrm{Kh}$ is enhanced by $0.4 \mathrm{~Sv}$, indicating the importance of the early-Holocene topography and ice sheets. The mechanism behind such change likely lies on two facts: On one hand, the signal of NAO + is more pronounced with the presence of LIS (Figure 9b and d); on the other hand, the cooling effect of LIS tends to increase the density of the North Atlantic subpolar water.

\section{Background freshwater flux along LIS coast}

The most pronounced feature in FWFC as compared with its prehosing state EH9 K (Figure 10a) is a general warming over the Labrador and Nordic seas in boreal winter, led by a northward shift of oceanic deep convection (Figure $4 \mathrm{e}$ and g). Also detected was a local cooling over the surface of the Gulf Stream and the Canary Current. With higher resolution applied, FWFCh shows no significant change in surface temperature (Figure 10c).
Due to the excessive simulated sea-ice cover over the Labrador Sea in FWFC, the freshwater advects along the Labrador Current, the Gulf Stream, and the Canary Current, forming a surface-freshening trough which acts as a lid on the sea water below (Figures 5e and 6e). The freshening pattern is located between $30^{\circ} \mathrm{N}$ and $50^{\circ} \mathrm{N}$ (Figures $6 \mathrm{e}$ and $8 \mathrm{e}$ ). The main deepwater formation sites, as depicted in Supplementary Figure S2 (available online), experience no significant changes, for which reason no obvious difference in the strength of ocean overturning circulation is found in FWFC (Figure 3). It is important to note that the sea water of the Arctic and North Atlantic subpolar regions is characterized by relatively cold water in the upper layer and warm water in the sublayer. As a consequence of the surface freshening, the upper layer around $30-50^{\circ} \mathrm{N}$ also experiences a negative salinity anomaly as shown in Figure 8e; this weakens local sinking of relatively cold sea water in the upper ocean, and the heat remains in the subsurface ocean. This is all accompanied by a cooling of up to $-2 \mathrm{~K}$ over the sea surface. Once the downward sinking of sea water over the freshening belt from $30^{\circ} \mathrm{N}$ to $50^{\circ} \mathrm{N}$ is repressed by the freshwater flux perturbation, sinking is enabled farther north in the Nordic and Barents seas where meltwater has no direct impact and conditions may favor water-mass formation. As a result, the (compared with the Arctic) relatively warmer, saltier sea surface water tends to flow to the north, leading to warming over the Nordic Sea and salinification across the Arctic Ocean.

Simulation FWFCh is similar to FWFC with respect to the main freshwater route it shows, which is along the Gulf Stream and the Canary Current. But unlike FWFC, the Labrador Sea in FWFCh is not covered by sea ice. The main deep-water formation sites (Supplementary Figure S2, available online) obtain a slight negative anomaly in SSS. The vertical ocean salinity profile indicates a fresher/denser North Atlantic north/south of $20^{\circ} \mathrm{N}$, which favors a weakened AMOC. Other processes in FWFCh just resemble those in FWFC, except that the subpolar warming is smaller in terms of both area and magnitude. 

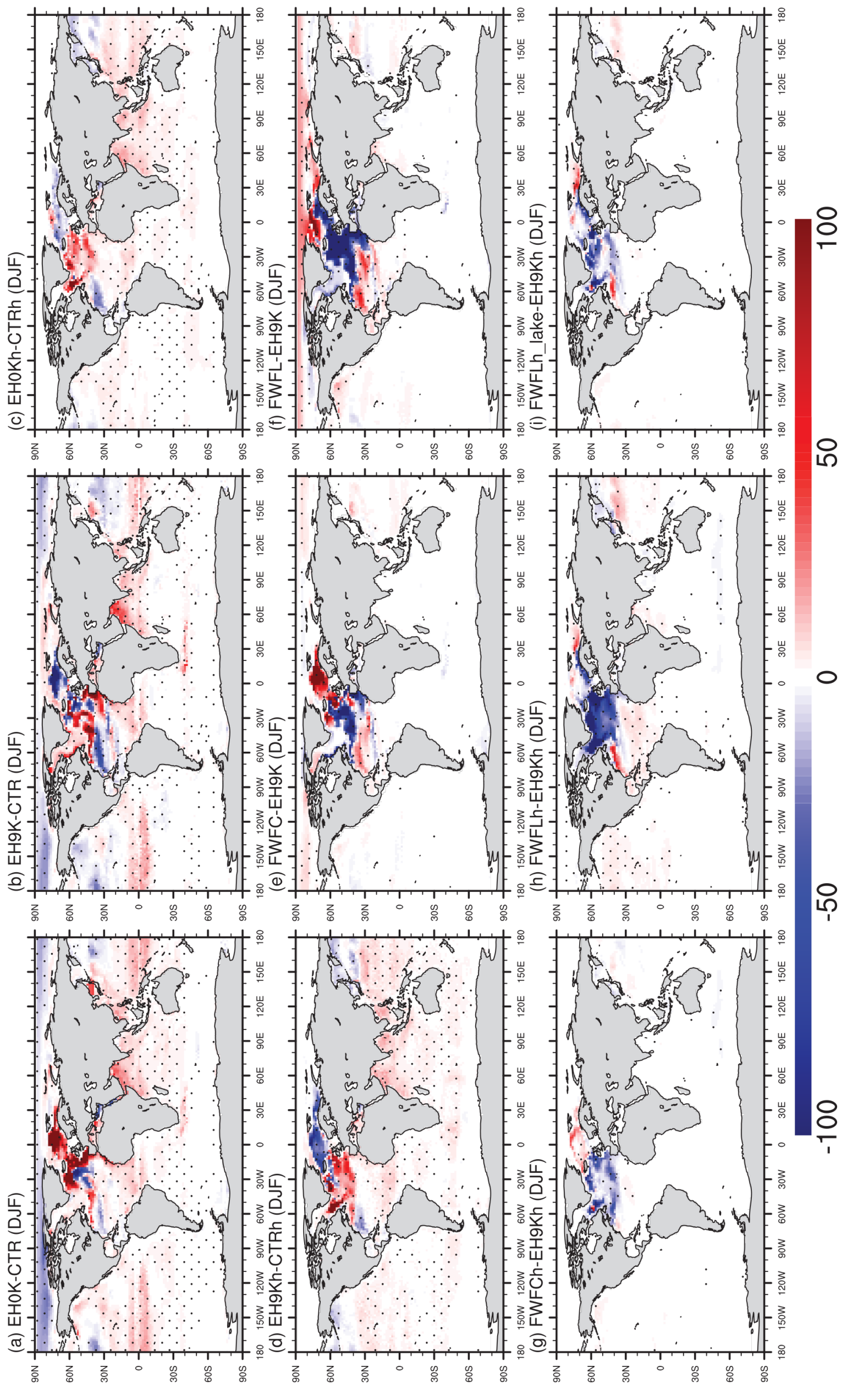

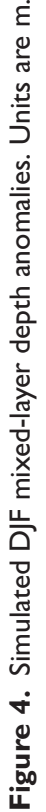




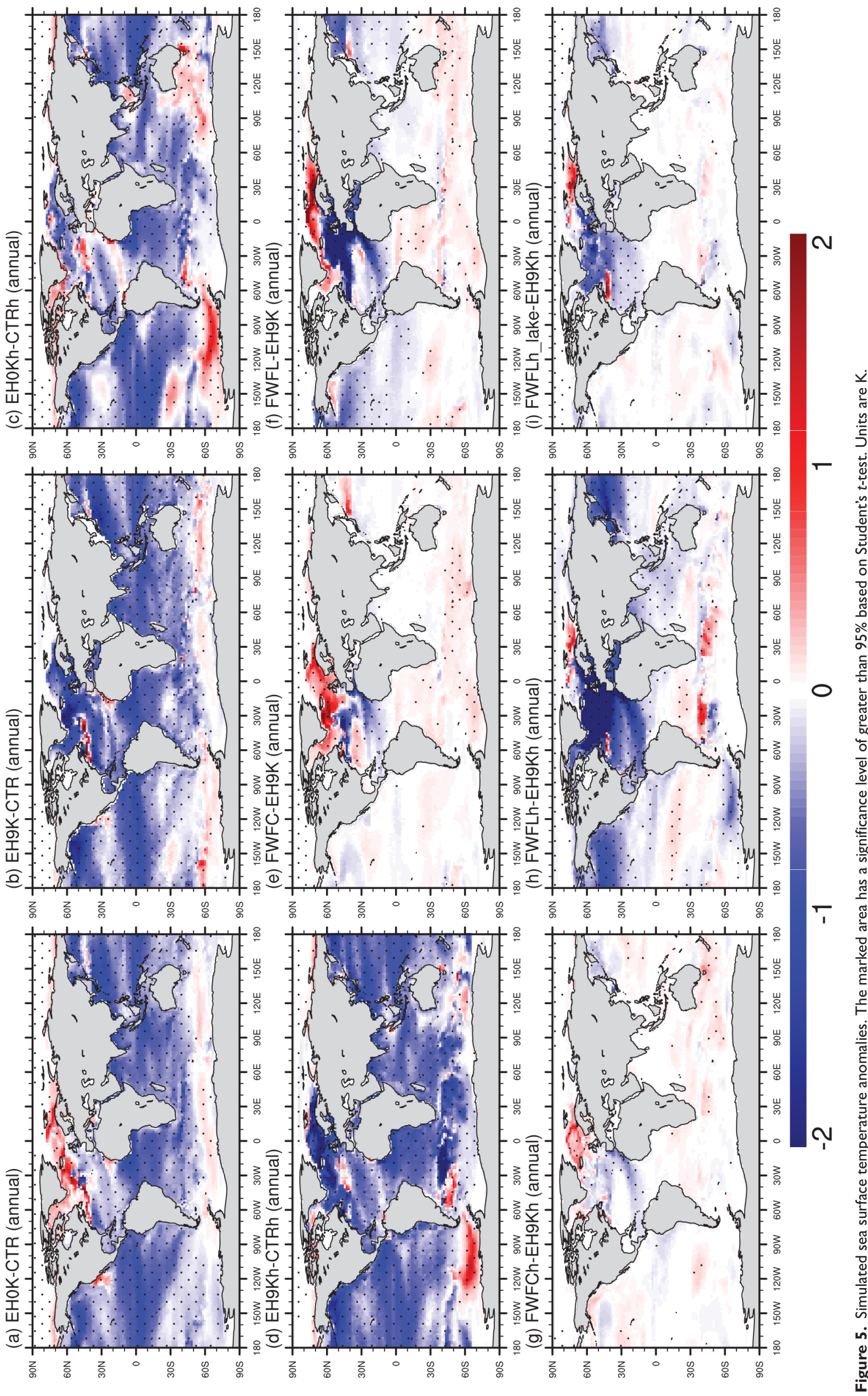



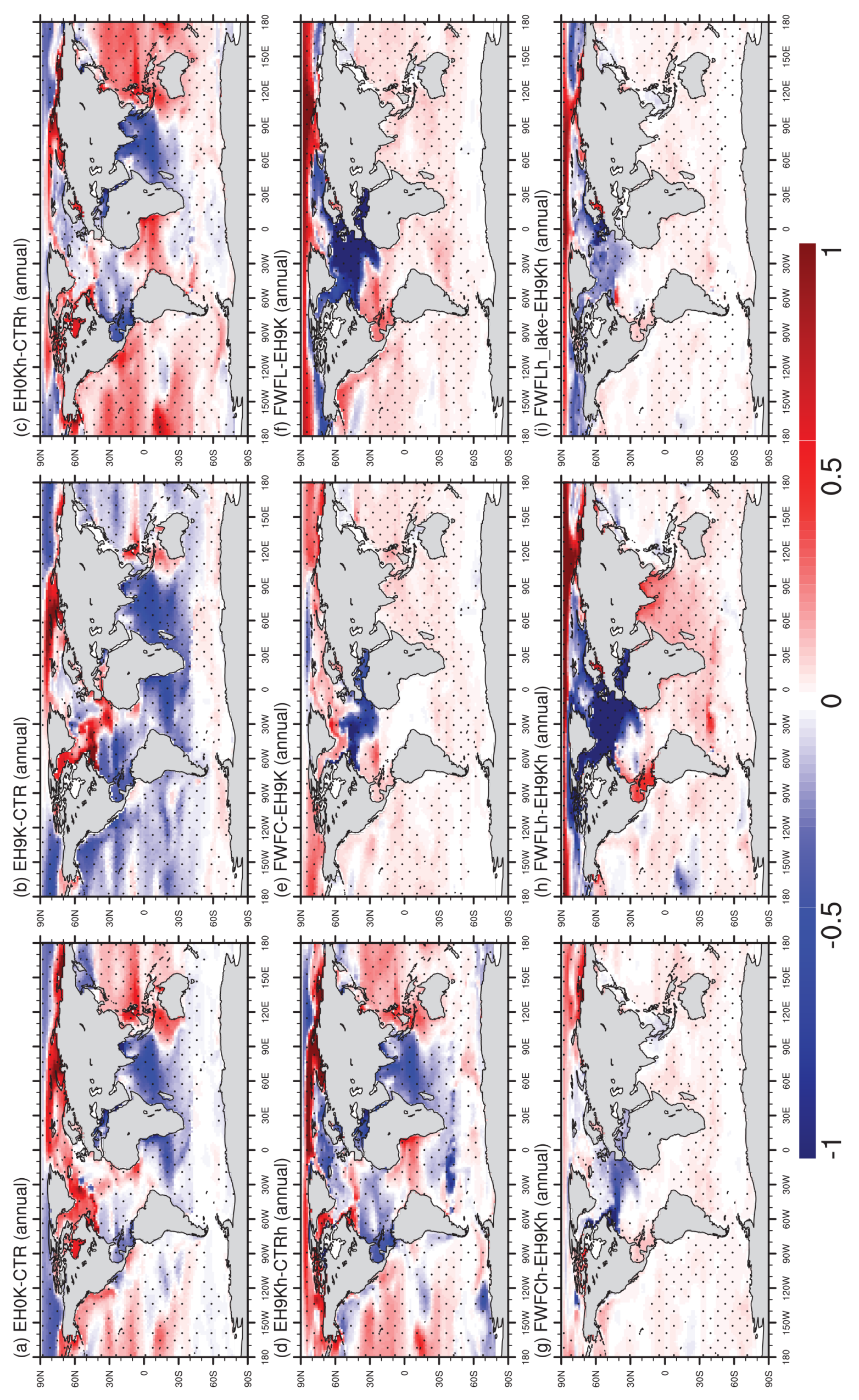

एक

0 .

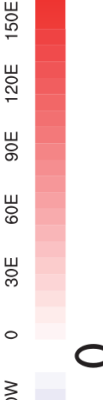

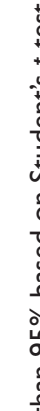



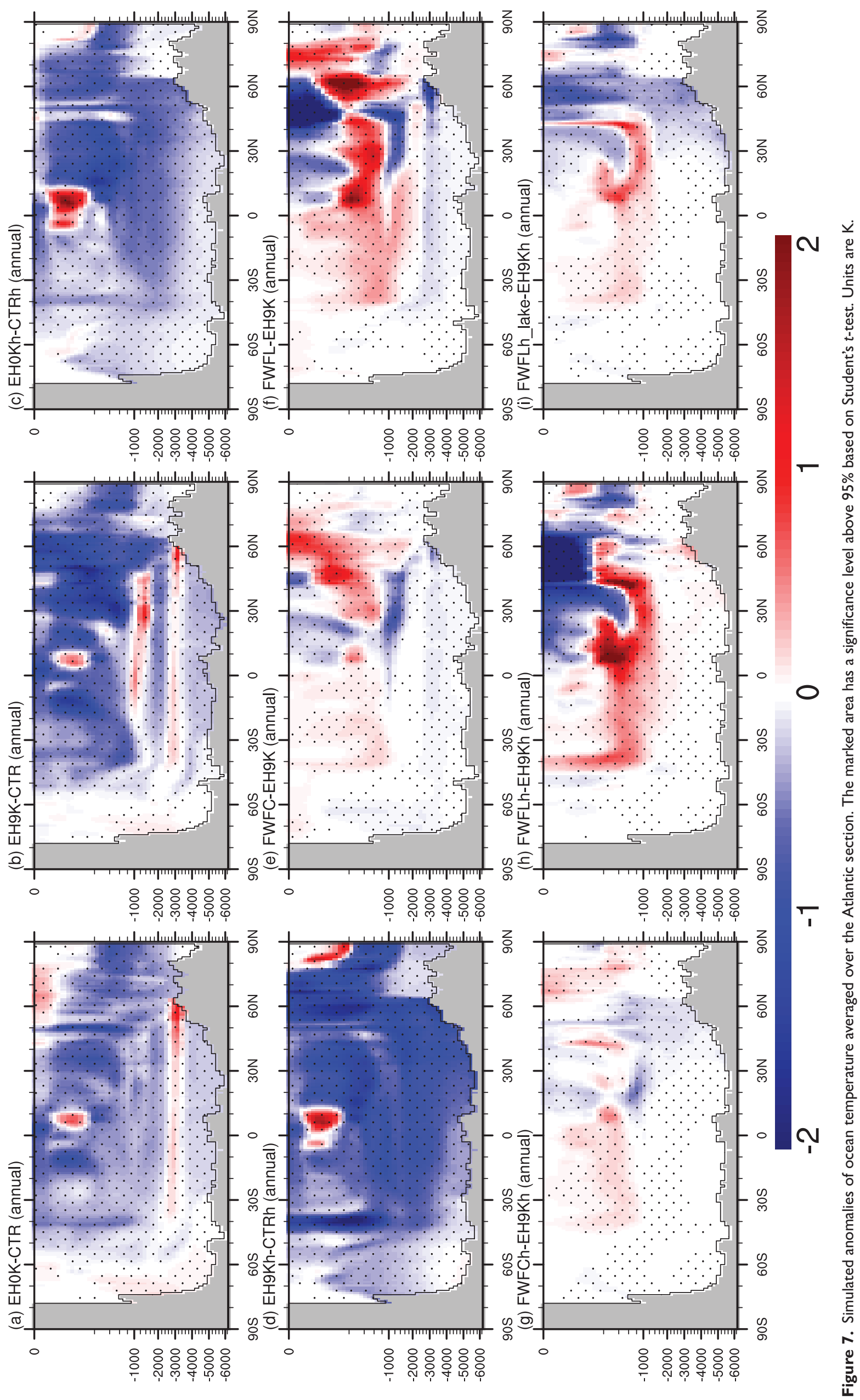

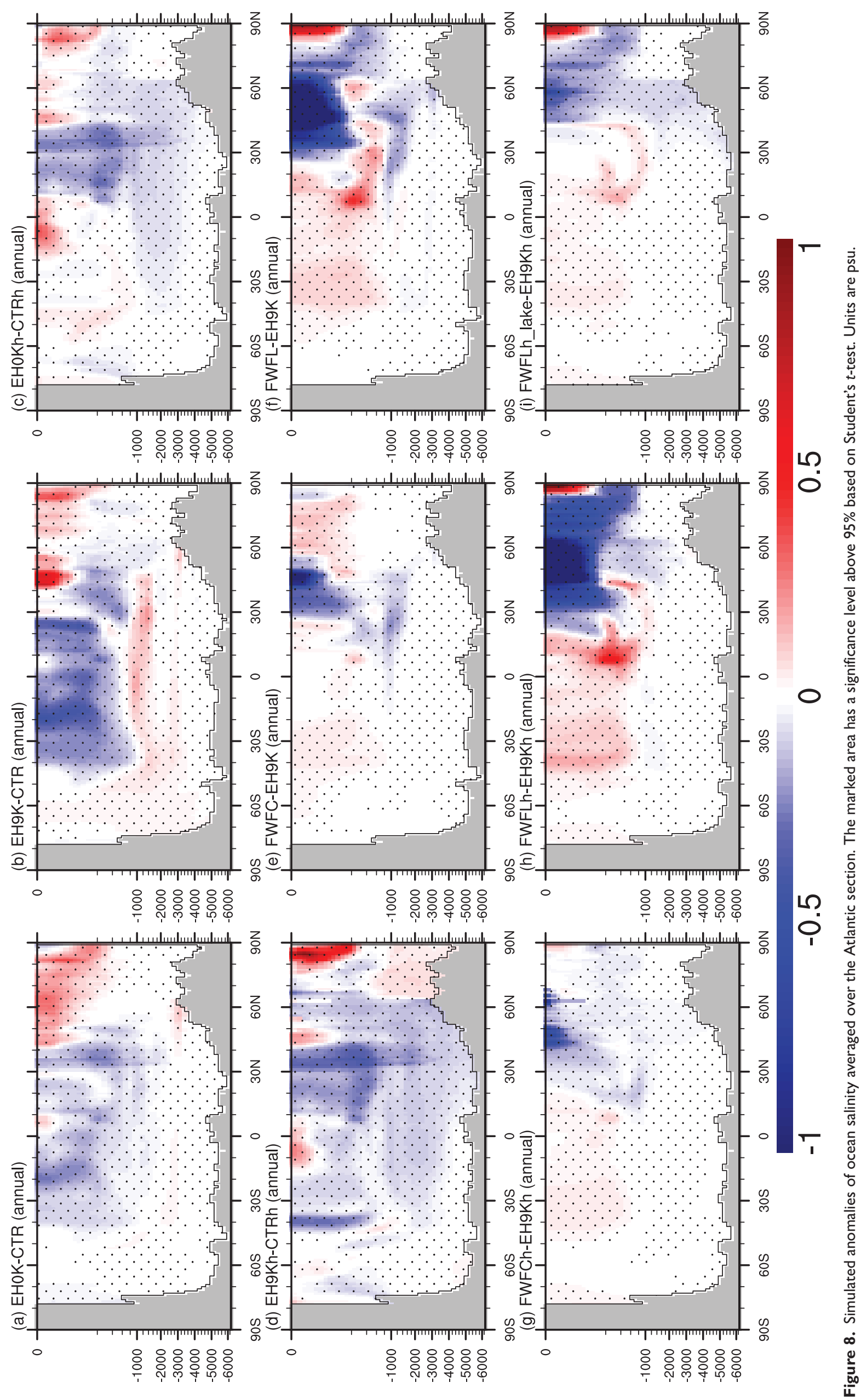

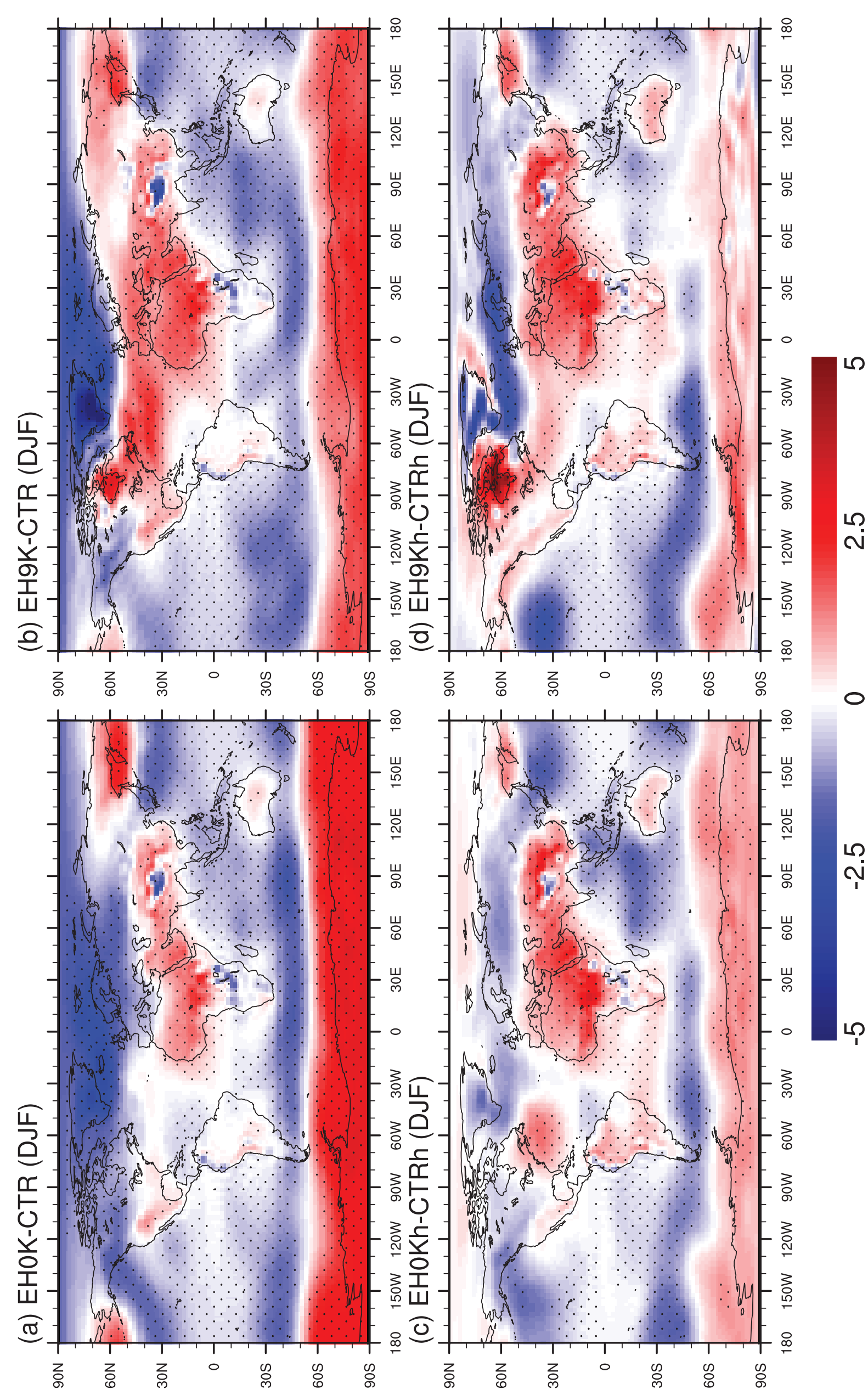

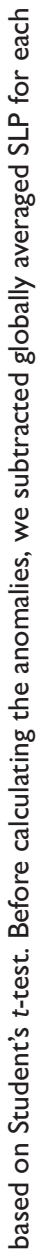

0 ㅇํํ ํํำ

ชัญ

옹

웜

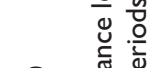

น

ר

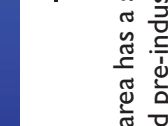

गु

है

L $\stackrel{2}{上}$ 웅

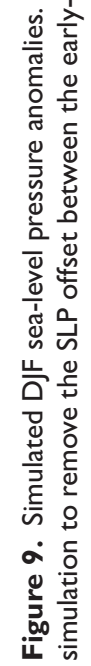


(a) FWFC-EH9K (annual)

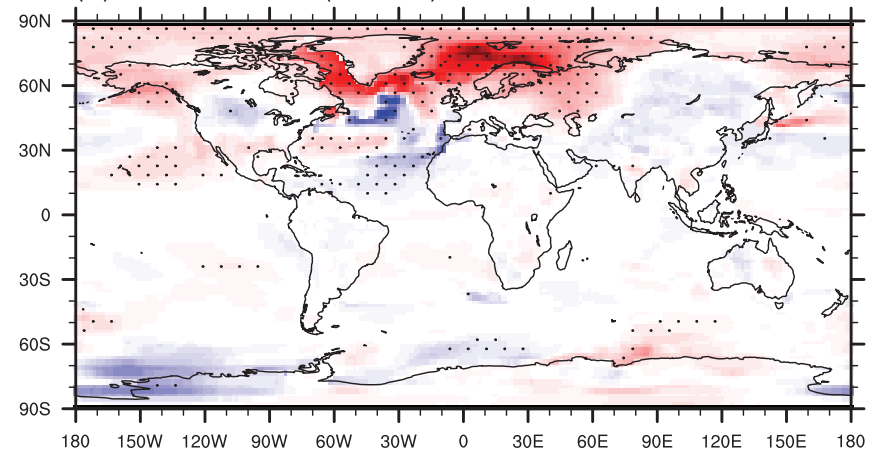

(c) FWFCh-EH9Kh (annual)

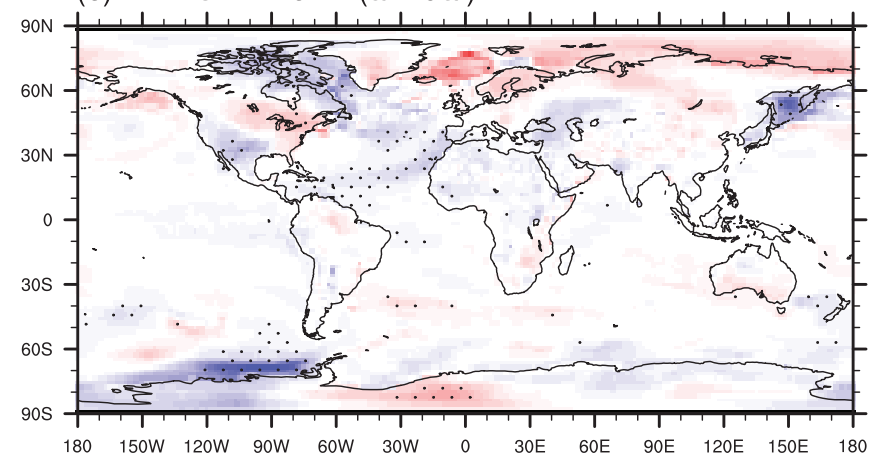

(e) FWFLh_lake-EH9Kh (annual)

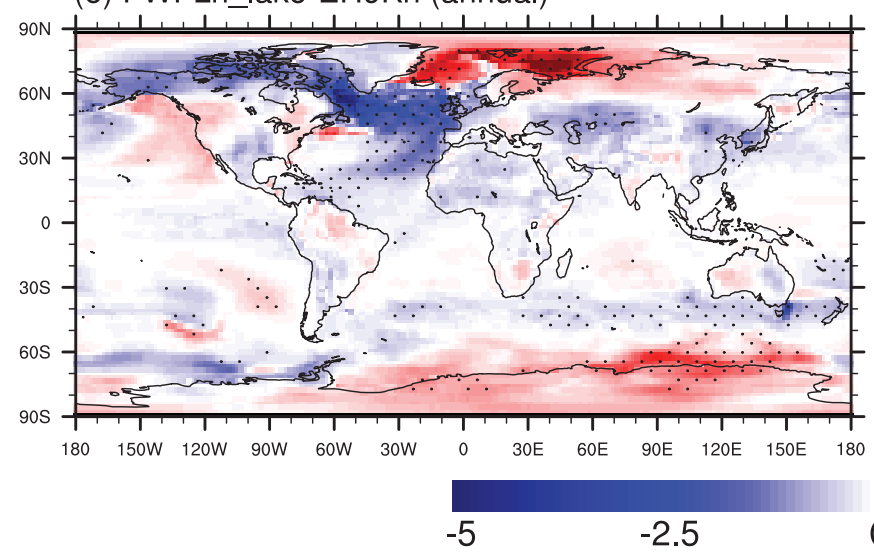

(b) FWFL-EH9K (annual)

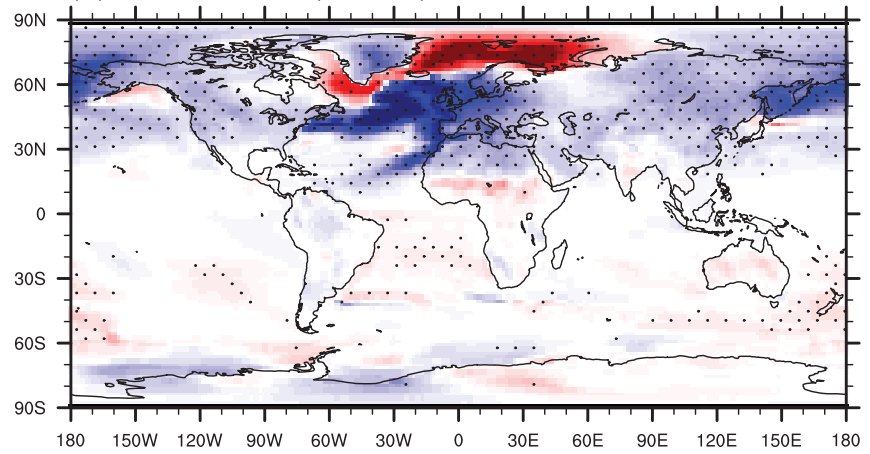

(d) FWFLh-EH9Kh (annual)

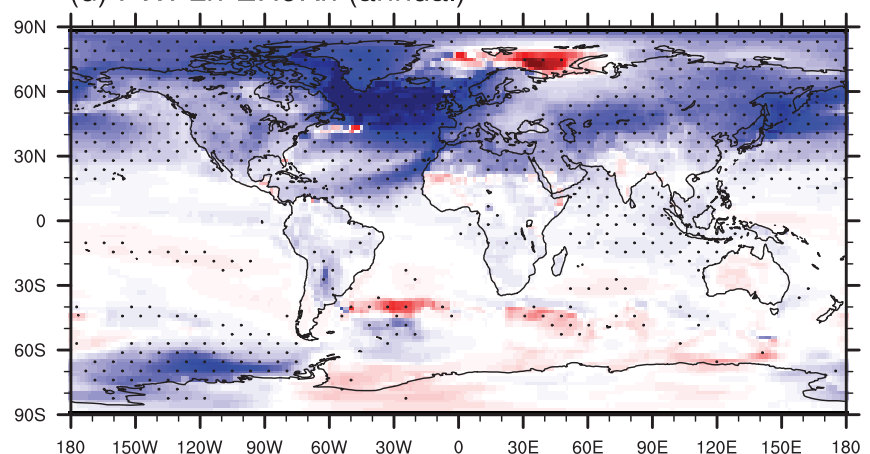

(f) FWFLh_lake-EH9Kh (annual)

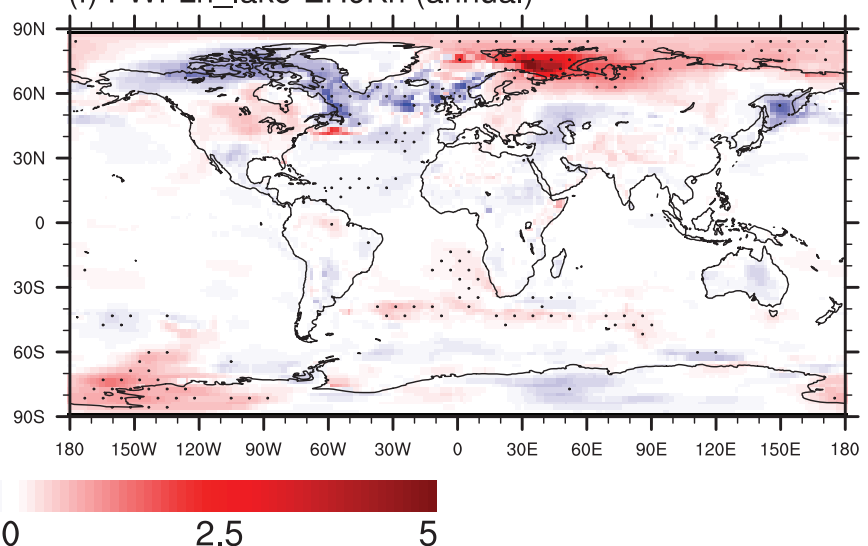

Figure 10. (a-d) Simulated annual mean surface temperature anomalies in hosing experiments with respect to their corresponding early-Holocene experiment for hosing years $7 \mathrm{I}-\mathrm{I00}$; (e, f) annual mean surface temperature anomalies between FWFLh_lake and CTRh for the (e) hosing years I-5 and (f) $7 I-100$. The marked area has the significance level of above $95 \%$ based on Student's $t$-test. Units are K.

\section{Background freshwater flux in the Labrador Sea}

Introducing freshwater into the Labrador Sea contributes to a pronounced cooling over the North Atlantic Ocean as well as the Bering Sea, as in Figure 10b, and to a warming over the Labrador and Nordic seas. No clear temperature response is seen in the tropics or in the Southern Hemisphere. Similarly, FWFLh shows a strong cooling over the Northern Hemisphere - with the most pronounced change located at the North Atlantic Ocean (Figure 10d) - as well as a local warming over the Barents Sea.

In terms of the oceanic responses, FWFL shows a significant decrease in SSS across the North Atlantic, with a maximum anomaly of less than -2 psu in the northeastern Atlantic, the main deep-water formation site. This tells us that glacial melting reinforces the stratification of the Atlantic Ocean and results in a lowstate AMOC. We observe a spin-down of the AMOC with a reduction to $60 \%$ of its pre-hosing strength within the first decade and then a more gradual but still continuing decline over the next 90 years (Figure 3 ). The weakened overturning circulation further suppresses heat exchange between the North Atlantic surface and the subsurface water masses, leading to a cooling in the upper ocean and a pronounced warming in the subsurface layer $\left(0-70^{\circ} \mathrm{N}\right)$. Another warming mechanism over the mid- to high latitudes of the North Atlantic subsurface layer lies in the fact that the AMOC diminishes at a slower rate than that at which the sea ice changes: The AMOC is still transporting heat northward into the North Atlantic subpolar region as sea ice expands and the fresh layer inhibits heat transfer from ocean to atmosphere. This warming spreads to north and induces a temperature change of more than $1 \mathrm{~K}$ across the subsurface of the Nordic and Barents seas $\left(70-80^{\circ} \mathrm{N}\right)$. Such subpolar warming has two effects on the ocean surface: (1) heat is transferred to the surface, causing a positive temperature anomaly over the Nordic and Barents seas; (2) subsurface warming enhances a local mixing visible in the increased MLD in Figure 4f. Another important reason for the subpolar warming - especially in the Labrador Sea - lies in the seasonality of sea-ice cover. The temperature of the sea surface when sea ice is present is around its freezing point. In the boreal winter, SSTs are slightly warmer in the Labrador Sea than in EH9 $\mathrm{K}$ as the region is covered by sea ice, and sea water freshening raises its freezing point. In boreal summer, sea ice over Labrador Sea vanishes and in the Nordic and Barents seas retreats northward, allowing a pronounced increase in the temperature of the 
open water at the surface as heat is transported from the ocean interior.

In general, in FWFLh, the surface sea water in the North Atlantic becomes fresher while the South Atlantic becomes saltier during the hosing; this resembles the pattern in the FWFL (lower resolution) experiment. Such a pattern of ocean salinity anomalies contributes to a decline in the AMOC, which further cools and freshens the upper ocean of the North Atlantic and forms the wellknown salinity-advection feedback (Stommel, 1961). The temperature anomalies in FWFLh (compared with its pre-hosing state) also share similarities with those in FWFL. But there is a clear exception that it simulates cooling (instead of warming) in the Labrador Sea. The reason is straightforward: Freshwater input over the Labrador Sea and the resulting reduction in the AMOC directly induce cooling across the hosing region. Moreover, warming over the Nordic Sea and the Barents Sea is much less pronounced than in the lower resolution model.

\section{Impact of catastrophic lake drainage}

In FWFLh lake, we observe a spin-down of the AMOC when the meltwater release occurs over the Labrador Sea (Figure 3), with a reduction to $70 \%$ of its pre-hosing strength within the first 5 years due to the strong, sudden freshwater flux, accompanied by a general decrease in MLD accross the North Atlantic Ocean. AMOC diminishes to about $11.5 \mathrm{~Sv}$, inducing a cooling of the North Atlantic surface and a warming of the Nordic Sea, the Barents Sea, and the subsurface water of the North Atlantic Ocean (Figure 10e). This phenomenon is similar to that found in FWFLh. Afterwards, a $0.13-\mathrm{Sv}$ freshwater input is not enough to maintain the stratification of the ocean, as colder surface water and the warmer sublayer water of the North Atlantic Ocean lead to stronger mixing and the AMOC begins to recover gradually but continuously, finally reaching a mean state of $14.5 \mathrm{~Sv}$ for hosing years 71-100 - approximately $2 \mathrm{~Sv}$ less than the prehosing state, which is not significant relative to decadal variability. With the recovery of the AMOC, the anomalies in surface temperature, SST, and SSS for the last 30 hosing years are much less pronounced (e.g. Figure 10f); indeed, the values in most regions are not even significant. One interesting phenomenon is that, despite the freshwater release, the southern flank of the Gulf Stream becomes warmer and saltier as a result of being displaced southward. The North Atlantic bottom water (NABW) moreover becomes cooler and fresher (Figures 6i and $8 \mathrm{i})$; this does not happen in other hosing experiments. This is to be expected: As the AMOC gradually recovers strength, more water mass can be transported from the surface to the deep ocean, and given that the negative temperature and salinity anomalies in the first hosing years, they gradually accumulate in the deep and bottom ocean, while in FWFLh, this mixing is suppressed by the weak mode of the AMOC.

\section{Discussion}

\section{Model resolution}

Model resolution is an important factor in climate models, as models with different resolutions can obtain opposite climatic responses to a given forcing (Shi and Lohmann, 2016). Traditional simulations of the paleoclimate are mostly based on relatively coarse resolutions in which a number of important small-scale processes, such as eddies and topographically influenced ocean currents, may not be presented explicitly. A comparison of transient simulations of the past 9000 years to proxy-based reconstructions indicates that localized changes recorded in those reconstructions are difficult to assess in a relatively low-resolution model because many important local features are likely to be missing (Blaschek et al., 2015). Here for the first time, we apply a state-of-the-art, high-resolution model, AWI-ESM, to simulations of the early Holocene. We apply an unstructured ocean grid with resolution varying from about $20 \mathrm{~km}$ in the Arctic (north of $50^{\circ} \mathrm{N}$ ) and in the tropics (around $0^{\circ} \mathrm{N}$ ) to about $150 \mathrm{~km}$ in parts of the open ocean. The ice-ocean component, FESOM, has the advantage of offering a regional focus within a global setup (Sidorenko et al., 2011). In principle, such a multi-resolution approach allows us to use enhanced horizontal resolution in dynamically active regions while otherwise keeping a coarseresolution setup otherwise (Sidorenko et al., 2015). The model has been validated in previous studies indicating good agreement between the modeled and the observational mean fields (Danabasoglu et al., 2016; Rackow et al., 2018; Scholz et al., 2013; Sidorenko et al., 2015; Wang et al., 2014).

High resolution can improve the behavior of the model in the following important ways: (1) In low-resolution models, it is hard to resolve the important basin-exchange through many key passages such as the CAA as the basins are too narrow. Our high-resolution model can capture the detailed information of the straits well. This is very important for representing the water-exchange through those key passages. (2) The MLD, as simulated by the high-resolution model, is shown in Supplementary Figure S2 (available online). It shows three main deepwater formation sites: the northeastern edge of North Atlantic Ocean, the Labrador Sea, and the eastern Nordic Sea. However, the low-resolution model only represents one main convection site over the northeastern North Atlantic. Convection in the Labrador Sea is strongly suppressed due to the simulated excessive sea-ice extent. (3) Applying low resolution, the AMOC maximum at $45^{\circ} \mathrm{N}$ is only slightly more than $13 \mathrm{~Sv}$, which is much weaker compared with most other stand-alone ocean and coupled climate models (Danabasoglu et al., 2014; Jungclaus et al., 2013), though still within the low-level range of estimation based on hydrographic data (Ganachaud and Wunsch, 2000). The AMOC maximum is $15.4 \mathrm{~Sv}$ in the high-resolution pre-industrial experiment, which is improved when compared with how the low-resolution model performed. In addition, comparing Figure $3 \mathrm{~b}$ and d, under modern state, the AMOC in the low-resolution model appears too weak and too shallow. Such a bias can be ameliorated by applying the high-resolution configuration. However, higher resolution does not ensure better behavior in every aspect of the simulated climate. A typical example in this paper is the warming over the Nordic and Barents seas in experiments FWFLh and FWFLh_lake, which is inconsistent with proxy records and with other, low-resolution climate models. But we can see that this warming bias in FWFLh is much weaker than in FWFL, and therefore conclude that the warming is related more to the physical processes represented in the model rather than to its resolution. Moreover, paleorecords suggest an increase in ocean salinity in the Nordic Sea (Came et al., 2007; de Vernal and Hillaire-Marcel, 2006; Rasmussen and Thomsen, 2010). Core data from RAPiD-12-1 $\mathrm{K}\left(62^{\circ} 05 \mathrm{~N}, 17^{\circ} 49 \mathrm{~W}\right)$ indicate a saltier subpolar North Atlantic (Thornalley et al., 2009). This salinity pattern is consistent with our coarse-resolution result. Our high-resolution model produces a freshened North Atlantic and Nordic Sea in the early Holocene as compared with the present, that is, the opposite of the coarse-resolution result and the proxy-based constructions. Such behavior of the model raises questions for the paleoclimate modeling community that aims to apply ever-higher spatial resolutions: Can a high-resolution model which performs better at simulating the modern climate than lower resolution models nonetheless improve the simulated paleoclimate fields? One may wonder whether it is really worth constantly increasing the resolution of models which thereby become more expensive and time-consuming but only offer limited improvements over lower resolution models. 


\section{Comparison with previous modeling studies}

In our model, the simulated early-Holocene surface temperature anomalies relative to pre-industrial conditions are primarily determined by orbital-scale insolation differences and by the melting of ice sheets. The more pronounced seasonality we find, including a general JJA warming and DJF cooling (especially over the continents of the Northern Hemisphere), agrees well with previous model studies (Kutzbach and Gallimore, 1988; Renssen et al., 2005; Weber, 2001; Wei and Lohmann, 2012; Zhang et al., 2016).

In this study, constant freshwater input into the Labrador Sea generates rapid weakening of the AMOC, which is similar to findings of previous studies (Matero et al., 2017; Wagner et al., 2013). However, our lake-release simulation yields a different AMOC response than former studies have done: In our model, the AMOC spins down due to proglacial lake drainage but the downspin is followed by a gradual recovery, whereas other studies indicate a continuous decline in the AMOC (Wagner et al., 2013). Furthermore, our experiments comparing the effects of freshwater released evenly across the Labrador Sea to freshwater injection along the western boundary of the North Atlantic find significant differences in how the ocean circulation responds: The former produces a major decline in the AMOC, while the latter yields no obvious effect on the strength of the thermohaline circulation. An earlier study had indicated instead that the weakening of the AMOC can happen no matter whether the freshwater enters the coastal region or the Labrador Sea - though that study examined pre-industrial conditions and posited a much higher freshwater flux of 1.75 Sv (Spence et al., 2008).

Previous model experiments exploring freshwater perturbation are consistent with proxy records in terms of cooling in the Northern Hemisphere at $8.2 \mathrm{k}$, which those models achieve by producing a weaker-than-average background AMOC (Wagner et al., 2013). Experiments without freshwater forcing obtain a stronger-than-present AMOC at 9k. Wei and Lohmann (2012) simulated a difference of $4 \mathrm{~Sv}$ between the early-Holocene and the pre-industrial AMOC using the coupled model COSMOS with a coarse resolution. The difference changes to $-3 \mathrm{~Sv}$ when the LIS is removed from the early-Holocene boundary conditions. A similar response in the AMOC is also obtained by a transient model integration (Liu et al., 2014). The warming over the Barents and Nordic seas we obtained (especially in our low-resolution model), as a response to freshwater input, differs from some previous studies (Renssen et al., 2002; Wei and Lohmann, 2012) that showed an overall cooling of the North Atlantic and Arctic oceans induced by glacial meltwater flux; but agrees with other models which have likewise obtained a warming over the Barents and Nordic seas when freshwater is introduced into the North Atlantic subpolar area (Stouffer et al., 2006), albeit under modern climate conditions.

\section{Model-proxy comparison}

Similar to our simulation results, enhanced $9 \mathrm{k}$ seasonality has been found in observations. For example, proxy data indicate a boreal-summer warming in northern Canada, northeastern and northwestern Europe, and central-west Siberia (Davis et al., 2003; Zhang et al., 2018). Moreover, carbon and oxygen isotopes document a cooling during the boreal-winter season over western continental Eurasia in the early Holocene relative to the present (Baker et al., 2017).

By examining molluscs, Mangerud and Svendsen (2018) show a warm period around Svalbard (6 K warmer in August than present-day) lasting from $11 \mathrm{k}$ to $9 \mathrm{k}$ and followed by a period of lower temperatures from $9 \mathrm{k}$ to $8.2 \mathrm{k}$. Sediment cores from the open ocean in Nordic seas adjacent to Svalbard support a similar conclusion (Aagaard-Sørensen et al., 2014; Hald et al., 2007; Risebrobakken et al., 2011; Sarnthein et al., 2003; Werner et al.,
2016). Besides higher summer-season insolation, the deglacial warming over the Nordic Sea and the Barents Sea also stems from climate-system-internal processes such as progressive invasion of warm Atlantic waters into this basin and changes in the oceanic conveyor belt (Duplessy et al., 2001; Risebrobakken et al., 2011). In this study, only the simulations forced only by $9 \mathrm{k}$ insolation and GHGs are able to capture such warming; while others, with 9k topography and ice sheets applied, show a cooling at various magnitudes. The reason behind such model behavior possibly lies on the fact that the cooling effect of LIS is overestimated in the model.

Much discussed during the last decade has been a short-lived cold event around 8.2k (Alley et al., 1997; Barber et al., 1999; Morrill et al., 2013a; van der Bilt et al., 2016) which may have been caused by a large meltwater pulse from the final collapse of the LIS. In this study, pronounced Northern Hemisphere cooling can be achieved in the simulations with freshwater input into the Labrador Sea. In contrast, coastal hosing experiments are not able to produce an abrupt weakening in AMOC which is essential for the cooling. In addition, our hosing simulations with freshwater input over the Labrador Sea represent warming across the northern Nordic Sea and Barents Sea which is more pronounced in the relatively coarse-resolution experiments. Such warming is associated with a northward shift of ocean deep convection and enhanced inflow from warmer North Atlantic sea water, which is similar to some other climate models (Stouffer et al., 2006). The warming over the Nordic and Barents seas in our hosing experiment aimed at producing the $8.2 \mathrm{k}$ event, however, is not consistent with the proxy constructions, all of which indicate an overall cooling at that time. This inconsistency is probably tied to the fact that the modeled subpolar temperature responds faster to the sublayer warming of the North Atlantic Ocean than it actually would: A warm-water pulse from the North Atlantic Ocean came only after $8.2 \mathrm{k}$ and then extended around almost the entire archipelago (Mangerud and Svendsen, 2018). But for this disagreement, our Labrador Sea hosing experiments produce results comparable to observational data which show a pronounced cooling over the northern North Atlantic (Moros et al., 2004) and eastern subtropical North Atlantic Ocean (Thornalley et al., 2009) in 8.2k.

Similar to AWI-ESM, previous model experiments can only capture the $8.2 \mathrm{k}$ event when run with a weaker backgound AMOC. However, some high-resolution records from the subpolar North Atlantic do not fully support the idea as they reveal no significant fluctuation in the AMOC during the early Holocene, though variability throughout the Holocene is found to be high (Hall et al., 2004; Oppo et al., 2003). Another study, moreover, using sediment grain size data to reconstruct past changes in the speed of deep-water flow, finds the $8.2 \mathrm{k}$ cooling accompanied by faster Iceland-Scotland overflow, which is an important component of the Atlantic thermohaline circulation. Analyzing grain size and benthic foraminifera, Praetorius et al. (2008) found that the Atlantic bottom currents abruptly weaken at $8.8 \mathrm{k}$ instead of $8.2 \mathrm{k}$. The stacked proxy record indicates that Iceland-Scotland overflow increased through the early Holocene, albeit with a minimum at $9.5-8 \mathrm{k}$, followed by a peak at $7 \mathrm{k}$ and then a gradual decline over the remainder of the Holocene (Thornalley et al., 2013). Based on low-temporal-resolution records, McManus et al. (2004) also show the possibility of a brief decline in the meridional overturning circulation from the Holocene to present, which agrees with Thornalley et al. (2013) and our simulation results, as our study shows an increase in $9 \mathrm{k}$ AMOC compared with the present.

\section{NAO and $A M O C$}

The early-Holocene experiments in this study all produce a tendency toward a positive NAO state compared with the present, 
which further affects the strength of the AMOC through changes in the North Atlantic deep convection and hydrological budget. Similarly, there are indications that variability in the NAO can have an important influence on deep convection in the Labrador Sea (Curry et al., 1998; Shi and Lohmann, 2016). The evolution of the atmospheric circulation profile over the North Atlantic section that is linked to the NAO is related to changes in the intensity and number of storms, which can be reflected in changes in the transport and convergence of atmospheric moisture and, hence, in the net distribution of precipitation (Dickson et al., 2000; Hurrell, 1995). Ocean observations and model simulations show that the changes in the thermohaline circulation during the last century have been driven by low-frequency variations in the NAO through changes in Labrador Sea convection (Latif et al., 2006). More recently, a delayed oscillator model as well as a climate model suggest that the NAO forces the AMOC on a 60-year cycle (Scholz et al., 2014; Sun et al., 2015). These studies all show an important relationship between the NAO and the Labrador Sea convection, and the results of our high-resolution simulation resemble them. At coarse resolution, however, the MLD in the Labrador Sea is shallow due to the excessive sea-ice cover, and the deep convection shifts to the northeastern North Atlantic. So far, some (but sparse) efforts have been made to reconstruct the Holocene NAO. Based on paleoenvironmental data, Lamy et al. (2006) indicate that NAO-like atmospheric variability was prominent during the Holocene beyond interannual to interdecadal timescales, which they attribute to orbital forcing. Model results mostly favor a positive NAO-like pattern in the early Holocene (Lorenz and Lohmann, 2004; Wei and Lohmann, 2012) relative to pre-industrial conditions.

\section{Others}

We should point out that our low- and high-resolution experiments use different versions of ice-sheet data. A reconstruction from the ice-sheet model ICE5G (VM2; Peltier, 2004) is used for the low-resolution model, and a more recent data set based on ICE6G (Peltier et al., 2015) is used for the high-resolution model. The ice-sheet extent in ICE6G is similar to that in ICE5G but with some minor modifications at the boundary regions of the ice sheets. ICE6G applies a lower elevation over the Antarctic continent than ICE5G does. There are also some improvements to the LIS elevation in ICE6G. Thus, ice-sheet elevation might also have affected the simulated climate along with the resolution of the models.

\section{Conclusion}

We have described the response of simulated oceanic and atmospheric circulation in the Northern Hemisphere to different earlyHolocene forcings (including insolation and GHGs) and how they combine with changed topography (including the presence of the LIS) as well as with a meltwater flux added either into the LIS coastal region or into the Labrador Sea. Our results are based on integrations performed with the state-of-the-art model AWI-ESM. In our study, we mainly focus on how surface properties and the AMOC respond to various early-Holocene forcings.

Our experiments consist of two independent groups which use the same atmospheric grid $\left(\mathrm{T} 63\right.$, about $\left.1.9^{\circ}\right)$ but at different oceanic resolutions. The number of surface nodes in the high-resolution ocean mesh (about 125,000) is more than three times as many as that in the lower resolution mesh (about 40,000).

Both resolution models reveal similar atmospheric patterns when the freshwater effects are left out: The early Holocene has more pronounced seasonality than the pre-industrial period, with the boreal-winter cooling and the summer warming (especially over the Northern Hemisphere continents) due to changes in insolation. The LIS can show an additional year-round cooling due to its high elevation and albedo. The tropical rain belt experiences more precipitation at its northern flank in both the tropical Atlantic and the Pacific oceans, indicating a northward displacement of the intertropical convergence zone (ITCZ). Wetter conditions over Africa and South Asia are a sign of an increased summer monsoon. Dry conditions appear over the North Atlantic Ocean, especially the Gulf Stream and the North Atlantic Drift. Such changes can be associated with SLP anomalies that illustrate a NAO-like mode.

As for oceanic responses, the two different oceanic-resolution models show discrepancies. For example, convection in the North Atlantic Ocean in the low-resolution model occurs mainly in the northwestern North Atlantic; but the high-resolution model instead shows three main deep-water convection sites - the Labrador Sea, the Irminger Sea, and the northeastern Nordic Sea. Moreover, even though the early-Holocene AMOC is higher than it is in the pre-industrial state in both models, the salinity anomaly patterns in the North Atlantic Ocean (which can affect the strength of the AMOC) are different. At low resolution, SSS in the North Atlantic Ocean is higher than in the pre-industrial state; the highresolution model, however, shows a slight freshening except over the Gulf Stream.

With glacial melting in the background, we find the location of the freshwater input to be very important. When the meltwater pulse is added over the coastal region of the LIS in our lower resolution model, the freshening only happens along the Labrador Current, the Gulf Stream, and the Canary Current, while no significant changes can be found in the northwestern North Atlantic Ocean. The AMOC shows no significant change compared with its pre-hosing state. But adding freshwater into the Labrador Sea leads to an overall freshening in the North Atlantic, and the AMOC experiences a spin-down of $60 \%$ which is observed in both the low-resolution and the high-resolution models. In addition, we find that, compared with a continuous $0.15 \mathrm{~Sv}$ freshwater input for 100 years in the Labrador Sea, a non-constant hosing amount (2.5 Sv for 1 year and then $0.13 \mathrm{~Sv}$ for 99 years $)$ - despite approximately equal total amounts of freshwater release (about $15 \mathrm{~Sv}$ ) - can produce a different result: The AMOC weakens by 5 $\mathrm{Sv}$ in the first years but then gradually recovers to a final condition of about $2 \mathrm{~Sv}$ less than in its pre-hosing state. Furthermore, all hosing experiments generate a warming in SST in the North Atlantic subpolar regions, caused by a northward shift in deep convection. Such warming is wider and stronger in the low-resolution model - with the anomaly being up to $2 \mathrm{~K}$ over Baffin Bay, the Labrador Sea, the Nordic Sea, and the Barents Sea - but much less pronounced in the high-resolution simulations, where a $1-\mathrm{K}$ warming appears only over the Barents Sea.

As a logical next step, we will perform early-Holocene simulations with an interactive climate-ice-sheet model in order to analyze the effect of the meltwater on the climate system. As we propose here, we are interested in analyzing the spatial heterogeneity of the early-Holocene climate.

\section{Acknowledgements}

The authors would like to thank Patrick Scholz and Qiang Wang for their technical assistance with the AWI-ESM (Alfred Wegener Institute-Earth System Model). They would also like to thank John A Foulks for helping to improve the language of the paper.

\section{Funding}

The author(s) disclosed receipt of the following financial support for the research, authorship, and/or publication of this article: This work was funded by the PACMEDY project of the Belmont Forum, the PALMOD project, and the open fund of State Key Laboratory of Loess and Quaternary Geology, Institute of Earth Environment, CAS (grant no. SKLLQG1920). 


\section{ORCID iD}

Xiaoxu Shi iD https://orcid.org/0000-0001-7793-9639

\section{Supplemental material}

Supplemental material for this article is available online.

\section{References}

Aagaard-Sørensen S, Husum K, Werner K et al. (2014) A Late Glacial-Early Holocene multiproxy record from the eastern Fram Strait, Polar North Atlantic. Marine Geology 355: 15-26.

Alley RB, Mayewski PA, Sowers T et al. (1997) Holocene climatic instability: A prominent, widespread event $8200 \mathrm{yr}$ ago. Geology 25(6): 483-486.

Argus DF, Peltier W, Drummond R et al. (2014) The Antarctica component of postglacial rebound model ICE-6G_C (VM5a) based on GPS positioning, exposure age dating of ice thicknesses, and relative sea level histories. Geophysical Journal International 198(1): 537-563.

Baker JL, Lachniet MS, Chervyatsova O et al. (2017) Holocene warming in western continental Eurasia driven by glacial retreat and greenhouse forcing. Nature Geoscience 10(6): 430-435.

Barber DC, Dyke A, Hillaire-Marcel C et al. (1999) Forcing of the cold event of 8,200 years ago by catastrophic drainage of Laurentide lakes. Nature 400(6742): 344-348.

Berger A (1978) Long-term variations of daily insolation and quaternary climatic changes. Journal of the Atmospheric Sciences 35(12): 2362-2367.

Bigelow NH, Brubaker LB, Edwards ME et al. (2003) Climate change and Arctic ecosystems: 1. vegetation changes north of $55^{\circ} \mathrm{N}$ between the last glacial maximum, mid-Holocene, and present. Journal of Geophysical Research 108(19): 8170.

Blaschek M, Renssen H, Kissel C et al. (2015) Holocene North Atlantic overturning in an atmosphere-ocean-sea ice model compared to proxy-based reconstructions. Paleoceanography 30(11): 1503-1524.

Box J, Fettweis X, Stroeve J et al. (2012) Greenland ice sheet albedo feedback: Thermodynamics and atmospheric drivers. The Cryosphere 6(4): 821-839.

Braconnot P, Otto-Bliesner B, Harrison S et al. (2007) Results of PMIP2 coupled simulations of the mid-Holocene and last glacial maximum-part 1: Experiments and large-scale features. Climate of the Past 3(2): 261-277.

Bradley RS (1990) Holocene paleoclimatology of the Queen Elizabeth Islands, Canadian High Arctic. Quaternary Science Reviews 9(4): 365-384.

Broccoli A and Manabe S (1987) The effects of the Laurentide ice sheet on North American climate during the last glacial maximum. Géographie Physique et Quaternaire 41(2): 291-299.

Came RE, Oppo DW and McManus JF (2007) Amplitude and timing of temperature and salinity variability in the subpolar North Atlantic over the past 10 k.y. Geology 35(4): 315-318.

Carlson AE, Clark PU, Haley BA et al. (2009) Routing of western Canadian Plains runoff during the 8.2 ka cold event. Geophysical Research Letters 36(14): L14704.

Carlson AE, LeGrande AN, Oppo DW et al. (2008) Rapid early Holocene deglaciation of the Laurentide ice sheet. Nature Geoscience 1(9): 620-624.

Crucifix M, Braconnot P, Harrison S et al. (2005) Second phase of paleoclimate modelling intercomparison project. Eos Transactions American Geophysical Union 86(28): 264-264.

Crucifix M, Loutre MF, Tulkens P et al. (2002) Climate evolution during the Holocene: A study with an earth system model of intermediate complexity. Climate Dynamics 19(1): 43-60.

Curry RG, McCartney MS and Joyce TM (1998) Oceanic transport of subpolar climate signals to mid-depth subtropical waters. Nature 391(6667): 575-577.
Danabasoglu G, Yeager SG, Bailey D et al. (2014) North Atlantic simulations in Coordinated Ocean-Ice Reference Experiments Phase II (CORE-II). Part I: Mean states. Ocean Modelling 73: $76-107$.

Danabasoglu G, Yeager SG, Kim WM et al. (2016) North Atlantic simulations in Coordinated Ocean-Ice Reference Experiments Phase II (CORE-II). Part II: Inter-annual to decadal variability. Ocean Modelling 97: 65-90.

Danilov S, Kivman G and Schröter J (2004) A finite element ocean model: Principles and evaluation. Ocean Modelling 6: $125-150$.

Davis B, Brewer S, Stevenson A et al. (2003) The temperature of Europe during the Holocene reconstructed from pollen data. Quaternary Science Reviews 22(15): 1701-1716.

de Vernal A and Hillaire-Marcel C (2006) Provincialism in trends and high frequency changes in the northwest North Atlantic during the Holocene. Global and Planetary Change 54(3): 263-290.

Dickson R, Osborn T, Hurrell J et al. (2000) The Arctic ocean response to the North Atlantic oscillation. Journal of Climate 13(15): 2671-2696.

Duplessy JC, Ivanova E, Murdmaa I et al. (2001) Holocene paleoceanography of the northern Barents Sea and variations of the northward heat transport by the Atlantic Ocean. Boreas 30(1): 2-16.

Ganachaud A and Wunsch C (2000) Improved estimates of global ocean circulation, heat transport and mixing from hydrographic data. Nature 408(6811): 453-457.

Hald M, Andersson C, Ebbesen H et al. (2007) Variations in temperature and extent of Atlantic water in the northern North Atlantic during the Holocene. Quaternary Science Reviews 26(25): 3423-3440.

Hall IR, Bianchi GG and Evans JR (2004) Centennial to millennial scale Holocene climate-deep water linkage in the North Atlantic. Quaternary Science Reviews 23(14-15): 1529-1536.

Hunke E and Dukowicz J (1997) An elastic-viscous-plastic model for sea ice dynamics. Journal of Physical Oceanography 27: $1849-1868$.

Hurrell JW (1995) Decadal trends in The North Atlantic oscillation: Regional temperatures and precipitation. Science 269(5224): 676-679.

Iacono MJ, Delamere JS, Mlawer EJ et al. (2008) Radiative forcing by long-lived greenhouse gases: Calculations with the AER radiative transfer models. Journal of Geophysical Research Atmospheres 113(13): D13103.

Jungclaus J, Fischer N, Haak H et al. (2013) Characteristics of the ocean simulations in the Max Planck Institute Ocean Model (MPIOM) the ocean component of the MPI-earth system model. Journal of Advances in Modeling Earth Systems 5(2): 422-446.

Klitgaard-Kristensen D, Sejrup HP, Haflidason H et al. (1998) A regional $8200 \mathrm{cal}$. yr BP cooling event in northwest Europe, induced by final stages of the Laurentide ice-sheet deglaciation? Journal of Quaternary Science 13(2): 165-169.

Köhler P, Nehrbass-Ahles C, Schmitt J et al. (2017) A 156 kyr smoothed history of the atmospheric greenhouse gases $\mathrm{CO}_{2}$, $\mathrm{CH}_{4}$, and $\mathrm{N}_{2} \mathrm{O}$ and their radiative forcing. Earth System Science Data 9(1): 363-387.

Kutzbach JE (1981) Monsoon climate of the early Holocene: Climate experiment with the earth's orbital parameters for 9000 years ago. Science 214(4516): 59-61.

Kutzbach JE and Gallimore R (1988) Sensitivity of a coupled atmosphere/mixed layer ocean model to changes in orbital forcing at 9000 years B.P. Journal of Geophysical Research: Atmospheres 93(D1): 803-821.

Kutzbach JE, Bonan G, Foley J et al. (1996) Vegetation and soil feedbacks on the response of the African monsoon to orbital forcing in the early to middle Holocene. Nature 384: 623-626. 
Lamy F, Arz HW, Bond GC et al. (2006) Multicentennial-scale hydrological changes in the Black Sea and northern Red Sea during the Holocene and the Arctic/North Atlantic Oscillation. Paleoceanography 21(1): PA1008.

Larocque I and Bigler C (2004) Similarities and discrepancies between chironomid-and diatom-inferred temperature reconstructions through the Holocene at lake 850, northern Sweden. Quaternary International 122(1): 109-121.

Latif M, Böning C, Willebrand J et al. (2006) Is the thermohaline circulation changing? Journal of Climate 19(18): 4631-4637.

Leppäranta M (1983) A growth model for black ice, snow ice and snow thickness in subarctic basins. Hydrology Research 14: 59-70.

Liu Z, Otto-Bliesner B, He F et al. (2009) Transient simulation of last deglaciation with a new mechanism for Bølling-Allerød warming. Science 325(5938): 310-314.

Liu Z, Zhu J, Rosenthal Y et al. (2014) The Holocene temperature conundrum. Proceedings of the National Academy of Sciences of the United States of America 111(34): 3501-3505.

Lorenz SJ and Lohmann G (2004) Acceleration technique for Milankovitch type forcing in a coupled atmosphere-ocean circulation model: Method and application for the Holocene. Climate Dynamics 23(7-8): 727-743.

Lott F (1999) Alleviation of stationary biases in a GCM through a mountain drag parameterization scheme and a simple representation of mountain lift forces. Monthly Weather Review 127(5): 788-801.

Loveland T, Reed B, Brown J et al. (2000) Development of a global land cover characteristics database and IGBP discover from $1 \mathrm{~km}$ AVHRR data. International Journal of Remote Sensing 21(6-7): 1303-1330.

Lu H, Yi S, Liu Z et al. (2013) Variation of East Asian monsoon precipitation during the past $21 \mathrm{ky}$ and potential $\mathrm{CO} 2$ forcing. Geology 41(9): 1023-1026.

McManus J, Francois R, Gherardi JM et al. (2004) Collapse and rapid resumption of Atlantic meridional circulation linked to deglacial climate changes. Nature 428(6985): 834-837.

Mangerud J and Svendsen JI (2018) The Holocene Thermal Maximum around Svalbard, Arctic North Atlantic; molluses show early and exceptional warmth. The Holocene 28(1): 65-83.

Matero I, Gregoire L, Ivanovic R et al. (2017) The 8.2 ka cooling event caused by Laurentide ice saddle collapse. Earth and Planetary Science Letters 473: 205-214.

Mitchell JF, Grahame N and Needham K (1988) Climate simulations for 9000 years before present: Seasonal variations and effect of the Laurentide ice sheet. Journal of Geophysical Research: Atmospheres 93(D7): 8283-8303.

Moros M, Emeis K, Risebrobakken B et al. (2004) Sea surface temperatures and ice rafting in the Holocene north Atlantic: Climate influences on northern Europe and Greenland. Quaternary Science Reviews 23(20-22): 2113-2126.

Morrill C, Anderson D, Bauer B et al. (2013a) Proxy benchmarks for intercomparison of $8.2 \mathrm{ka}$ simulations. Climate of the Past 9(1): 423-432.

Morrill C, Legrande AN, Renssen H et al. (2013b) Model sensitivity to North Atlantic freshwater forcing at $8.2 \mathrm{ka}$. Climate of the Past 9: 955-968.

Mügler I, Gleixner G, Günther F et al. (2010) A multi-proxy approach to reconstruct hydrological changes and Holocene climate development of Nam Co, Central Tibet. Journal of Paleolimnology 43(4): 625-648.

Myhre G, Highwood EJ, Shine KP et al. (1998) New estimates of radiative forcing due to well mixed greenhouse gases. Geophysical Research Letters 25(14): 2715-2718.

Oppo DW, McManus JF and Cullen JL (2003) Palaeo-oceanography: Deepwater variability in the Holocene epoch. Nature 422(6929): 277.
Otto-Bliesner BL, Braconnot P, Harrison SP et al. (2017) The PMIP4 contribution to CMIP6-Part 2: Two interglacials, scientific objective and experimental design for Holocene and Last Interglacial Simulations. Geoscientific Model Development 10(11): 3979-4003.

Owens W and Lemke P (1990) Sensitivity studies with a sea icemixed layer-pycnocline model in the Weddel Sea. Journal of Geophysical Research 95(C6): 9527-9538.

Parkinson C and Washington W (1979) A large-scale numerical model of sea ice. Journal of Geophysical Research 84(C1): $311-337$

Peltier W (2004) Global glacial isostasy and the surface of the iceage Earth: The ICE-5G (VM2) model and GRACE. Annual Review of Earth and Planetary Sciences 32: 111-149.

Peltier W, Argus D and Drummond R (2015) Space geodesy constrains ice age terminal deglaciation: The global ICE-6G C (VM5a) model. Journal of Geophysical Research: Solid Earth 120(1): 450-487.

Praetorius SK, McManus JF, Oppo DW et al. (2008) Episodic reductions in bottom-water currents since the last ice age. Nature Geoscience 1(7): 449-452.

Rackow T, Goessling HF, Jung T et al. (2018) Towards multiresolution global climate modeling with ECHAM6-FESOM. Part II: Climate variability. Climate Dynamics 50(7-8): 2369-2394.

Raddatz T, Reick C, Knorr W et al. (2007) Will the tropical land biosphere dominate the climate-carbon cycle feedback during the twenty-first century? Climate Dynamics 29(6): 565-574.

Rao Z, Huang C, Xie L et al. (2019) Long-term summer warming trend during the Holocene in central Asia indicated by alpine peat $\alpha$-cellulose $\delta 13 \mathrm{C}$ record. Quaternary Science Reviews 203: 56-67.

Rasmussen TL and Thomsen E (2010) Holocene temperature and salinity variability of the Atlantic water inflow to the Nordic seas. The Holocene 20(8): 1223-1234.

Raynaud D, Barnola J, Chappellaz J et al. (2000) The ice record of greenhouse gases: A view in the context of future changes. Quaternary Science Reviews 19(1-5): 9-17.

Redi M (1982) Oceanic isopycnal mixing by coordinate rotation. Journal of Physical Oceanography 12: 1154-1158.

Renssen H, Goosse H and Fichefet T (2002) Modeling the effect of freshwater pulses on the early Holocene climate: The influence of high-frequency climate variability. Paleoceanography 17(2): 10-11.

Renssen H, Goosse H, Fichefet T et al. (2001) The 8.2 kyr BP event simulated by a Global Atmosphere-sea-Ice-Ocean Model. Geophysical Research Letters 28(8): 1567-1570.

Renssen H, Goosse H, Fichefet T et al. (2005) Simulating the Holocene climate evolution at northern high latitudes using a coupled atmosphere-sea ice-ocean-vegetation model. Climate Dynamics 24(1): 23-43.

Renssen H, Seppä H, Heiri O et al. (2009) The spatial and temporal complexity of the Holocene thermal maximum. Nature Geoscience 2(6): 411-414.

Risebrobakken B, Dokken T, Smedsrud LH et al. (2011) Early Holocene temperature variability in the Nordic Seas: The role of oceanic heat advection versus changes in orbital forcing. Paleoceanography and Paleoclimatology 26(4): PA4206.

Roeckner E, Dümenil L, Kirk E et al. (1989) The Hamburg version of the ECMWF model (ECHAM). Technical Report 13: $7-1$.

Sarnthein M, Van Kreveld S, Erlenkeuser H et al. (2003) Centennial-to-millennial-scale periodicities of Holocene climate and sediment injections off the western Barents shelf, $75^{\circ} \mathrm{N}$. Boreas 32(3): 447-461.

Scholz P, Kieke D, Lohmann G et al. (2014) Evaluation of Labrador Sea Water formation in a global Finite-Element Sea-Ice 
Ocean Model setup, based on a comparison with observational data. Journal of Geophysical Research: Oceans 119(3): 1644-1667.

Scholz P, Lohmann G, Wang Q et al. (2013) Evaluation of a Finite-Element Sea-Ice Ocean Model (FESOM) set-up to study the interannual to decadal variability in the deep-water formation rates. Ocean Dynamics 63(4): 347-370.

Semtner A (1976) A model for the thermodynamic growth of sea ice in numerical investigations of climate. Journal of Physical Oceanography 6(3): 379-389.

Shi X and Lohmann G (2016) Simulated response of the midHolocene Atlantic meridional overturning circulation in ECHAM6-FESOM/MPIOM. Journal of Geophysical Research: Oceans 121(8): 6444-6469.

Sidorenko D, Rackow T, Jung T et al. (2015) Towards multi-resolution global climate modeling with ECHAM6-FESOM. Part I: Model formulation and mean climate. Climate Dynamics 44(3-4): 757-780.

Sidorenko D, Wang Q, Danilov S et al. (2011) FESOM under coordinated ocean-ice reference experiment forcing. Ocean Dynamics 61: 881-890.

Spence JP, Eby M and Weaver AJ (2008) The sensitivity of the Atlantic meridional overturning circulation to freshwater forcing at eddy-permitting resolutions. Journal of Climate 21(11): 2697-2710.

Stevens B, Giorgetta M, Esch M et al. (2013) Atmospheric component of the MPI-M earth system model: ECHAM6. Journal of Advances in Modeling Earth Systems 5: 146-172.

Stommel H (1961) Thermohaline convection with two stable regimes of flow. Tellus 13(2): 224-230.

Stouffer RJ, Yin J, Gregory J et al. (2006) Investigating the causes of the response of the thermohaline circulation to past and future climate changes. Journal of Climate 19(8): $1365-1387$.

Sun C, Li J and Jin FF (2015) A delayed oscillator model for the quasi-periodic multidecadal variability of the NAO. Climate Dynamics 45(7-8): 2083-2099.

Sundqvist H, Berge E and Kristjánsson JE (1989) Condensation and cloud parameterization studies with a mesoscale numerical weather prediction model. Monthly Weather Review 117(8): 1641-1657.

Thornalley DJ, Blaschek M, Davies FJ et al. (2013) Long-term variations in Iceland-Scotland overflow strength during the Holocene. Climate of the Past 9(5): 2073-2084.

Thornalley DJ, Elderfield H and McCave IN (2009) Holocene oscillations in temperature and salinity of the surface subpolar North Atlantic. Nature 457(7230): 711-714.

Timmermann R, Danilov S, Schröter J et al. (2009) Ocean circulation and sea ice distribution in a finite element global sea ice-ocean model. Ocean Modelling 27: 114-129.
Valcke S, Craig T and Coquart L (2013) OASIS3-MCT user guide, OASIS3-MCT 2.0. CERFACS/CNRS SUC URA. Available at: http://www.cerfacs.fr/oa4web/oasis3-mct_3.0/ oasis3mct_UserGuide.pdf.

van der Bilt WG, D'Andrea WJ, Bakke J et al. (2016) Alkenonebased reconstructions reveal four-phase Holocene temperature evolution for High Arctic Svalbard. Quaternary Science Reviews 183: 204-213.

Von Grafenstein U, Erlenkeuser H, Müller J et al. (1998) The cold event 8200 years ago documented in oxygen isotope records of precipitation in Europe and Greenland. Climate Dynamics 14(2): 73-81.

Wagner AJ, Morrill C, Otto-Bliesner BL et al. (2013) Model support for forcing of the $8.2 \mathrm{ka}$ event by meltwater from the Hudson Bay ice dome. Climate Dynamics 41(11-12): 2855-2873.

Wang Q, Danilov S, Sidorenko D et al. (2014) The Finite Element Sea Ice-Ocean Model (FESOM): Formulation of an unstructured-mesh ocean general circulation model. Geoscientific Model Development 7: 663-693.

Weber S (2001) The impact of orbital forcing on the climate of an intermediate-complexity coupled model. Global and Planetary Change 30(1): 7-12.

Weber S and Oerlemans J (2003) Holocene glacier variability: Three case studies using an intermediate-complexity climate model. The Holocene 13(3): 353-363.

Weber S, Crowley T and Van der Schrier G (2004) Solar irradiance forcing of centennial climate variability during the Holocene. Climate Dynamics 22(5): 539-553.

Wei W and Lohmann G (2012) Simulated Atlantic multidecadal oscillation during the Holocene. Journal of Climate 25(20): 6989-7002.

Wekerle C (2013) Dynamics of the Canadian arctic archipelago throughflow: A numerical study with a finite element sea ice and ocean model. PhD Thesis, Alfred-Wegener-Institut, Universitaet Bremen.

Werner K, Müller J, Husum K et al. (2016) Holocene sea subsurface and surface water masses in the Fram Strait-Comparisons of temperature and sea-ice reconstructions. Quaternary Science Reviews 147: 194-209.

Zhang X, Lohmann G, Knorr G et al. (2014) Abrupt glacial climate shifts controlled by ice sheet changes. Nature 512: 290-294.

Zhang Y, Renssen H, Seppä H et al. (2016) Effects of melting ice sheets and orbital forcing on the early Holocene warming in the extratropical northern hemisphere. Climate of the Past 12: $1119-1135$.

Zhang Y, Renssen H, Seppä H et al. (2018) Holocene temperature trends in the extratropical northern hemisphere based on inter-model comparisons. Journal of Quaternary Science 33(4): 464-476. 